\title{
Chapter 4 \\ Socioeconomic Achievement Gaps: Trend Results for Education Systems
}

\begin{abstract}
This study compared the SES achievement gaps of 13 education systems in both mathematics and science over time. Each education system was initially categorized as either a system with "increasing SES achievement gaps" or "decreasing SES achievement gaps," based on 20-year trends in the IEA's Trends in International Mathematics and Science Study (TIMSS). For example, achievement gaps between low- and high-SES students significantly widened over this time in Hungary, Islamic Republic of Iran, Lithuania, and Singapore, while in Norway, Slovenia, and the United States, student achievement gaps in either mathematics or science narrowed between 1995 and 2015. Education system specific graphs show trends in the achievement gaps between high- and low-SES students, as well as trends for low-SES students reaching the TIMSS intermediate benchmark over time. Monitoring intermediate changes between 1995 and 2003, and between 2003 and 2015, as well as in-depth analysis of relevant country-specific macroeconomic indicators for each education system, provides further context.
\end{abstract}

Keywords Achievement gaps · Disadvantaged students · Educational inequality · International large-scale assessment $\cdot$ Macroeconomic indicators $\cdot$ Socioeconomic status (SES) · Trends in International Mathematics and Science Study (TIMSS)

\subsection{Overall Findings}

Our first research question asked to what extent inequality of education outcomes due to $\mathrm{SES}^{* 1}$ had changed for the 13 education systems from 1995 to 2015 . To answer this, we calculated the achievement gap over time between students

\footnotetext{
${ }^{1}$ The SES measure used in this study is a modified version of the TIMSS home educational resources (HER) index and does not represent the full SES construct, as usually defined by parental education, family income, and parental occupation. In this report, we therefore term our measure SES* to denote the conceptual difference (Please refer to Chap. 1 for more details).
} 
categorized in high- and low-SES* groups in terms of their average mathematics and science scores. Larger gaps suggest that SES* plays a larger role in educational outcomes in that education system.

Some systems presented a linear change, while others experienced some ups and downs in terms of trend. Among the 13 education systems selected for study, we observed two general patterns: overall, SES* achievement gaps were either increasing or decreasing, although there were variations in the magnitude of differences (Table 4.1).

As mentioned, to provide better context for understanding the results, we also looked in-depth at the country-specific findings. The educational and macroeconomic context is critical to an understanding of trend changes in SES* gaps, as well as the changes between intermediate cycles of TIMSS (readers should refer to Table 3.6 for further information on the sources for such data). We also determined what percentage of low-SES* students achieved at or above the TIMSS international intermediate benchmark for mathematics and science (475 points; Tables 4.2 and 4.3).

\subsubsection{Increasing SES* Achievement Gap}

Six education systems demonstrated an overall increase in the achievement gap in mathematics between high- and low-SES* students between 1995 and 2015 (Fig. 4.1); for three education systems (Hungary, Iran, and Singapore), the results are statistically significant. For example, in Hungary, the achievement gap in mathematics was already high at 103 points in 1995 , and had increased to 143 points by 2015 . This was an improvement of about one-half of a standard deviation (100 points).

Similarly, our results show the achievement gap in science between high- and low-SES* students increased in Hungary, Iran, and Lithuania, confirming this trend (Fig. 4.2). For instance, in Iran, the difference in the science score between high- and low-SES* students increased from 41 points in 1995 to 104 points in 2015. This suggests that family background plays an increasingly important role regarding students' academic outcomes in Iran.

\subsubsection{Decreasing SES* Achievement Gap}

Seven education systems seem to have experienced an overall decrease in the achievement gap in mathematics between high- and low-SES* students between 1995 and 2015 (Fig. 4.3). However, we only identified statistically significant changes in Norway and Slovenia. As an example, the mathematics achievement gap between high- and low-SES* students in Norway was 63 points in 1995, declining to 50 points in 2015 . 







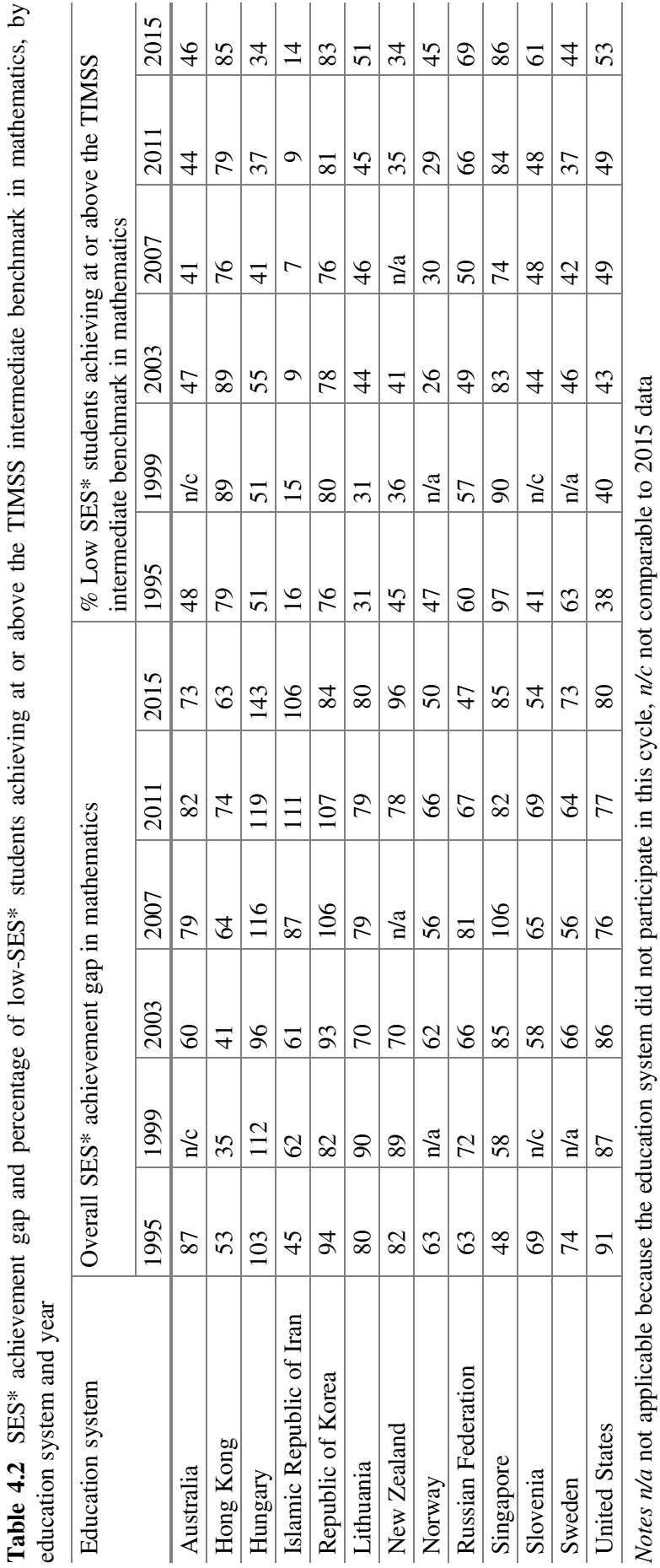




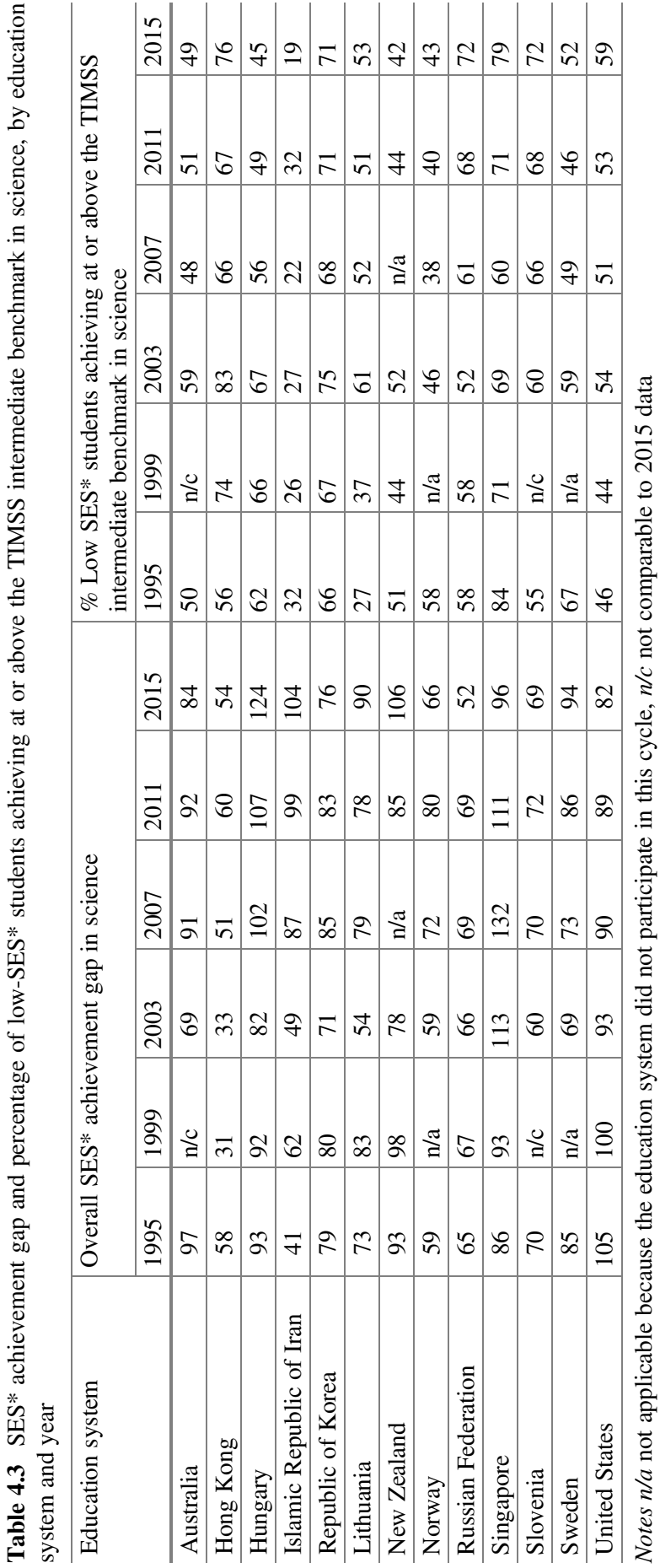




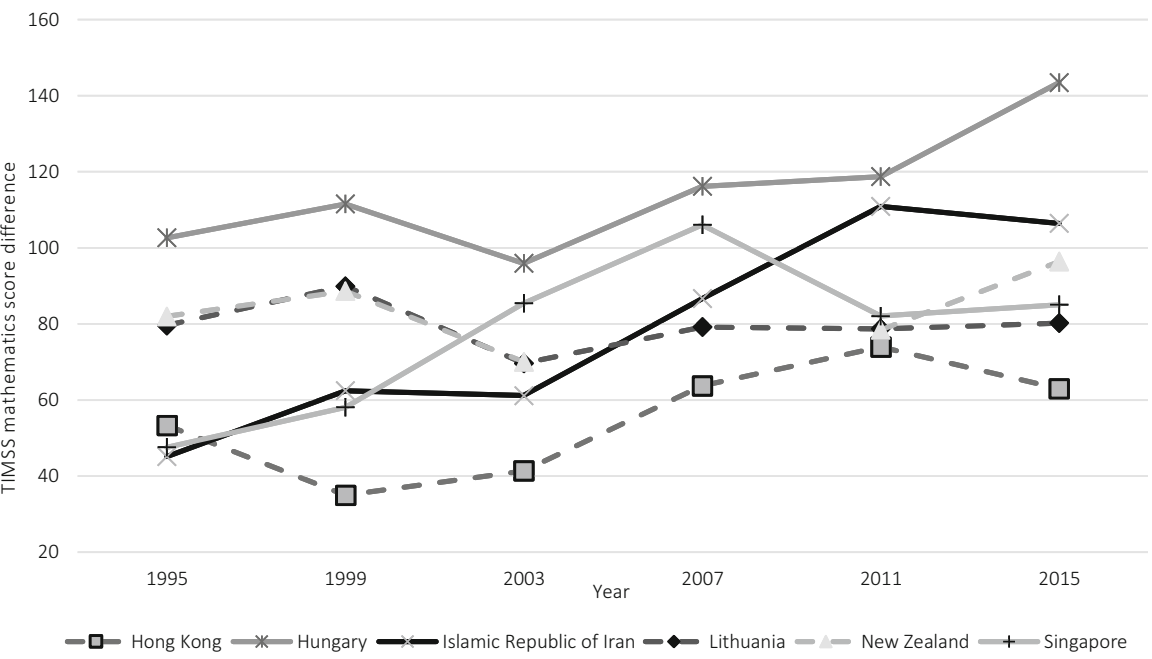

Fig. 4.1 Education systems showing an increasing mathematics score difference between highand low-SES* students over 20 years of TIMSS

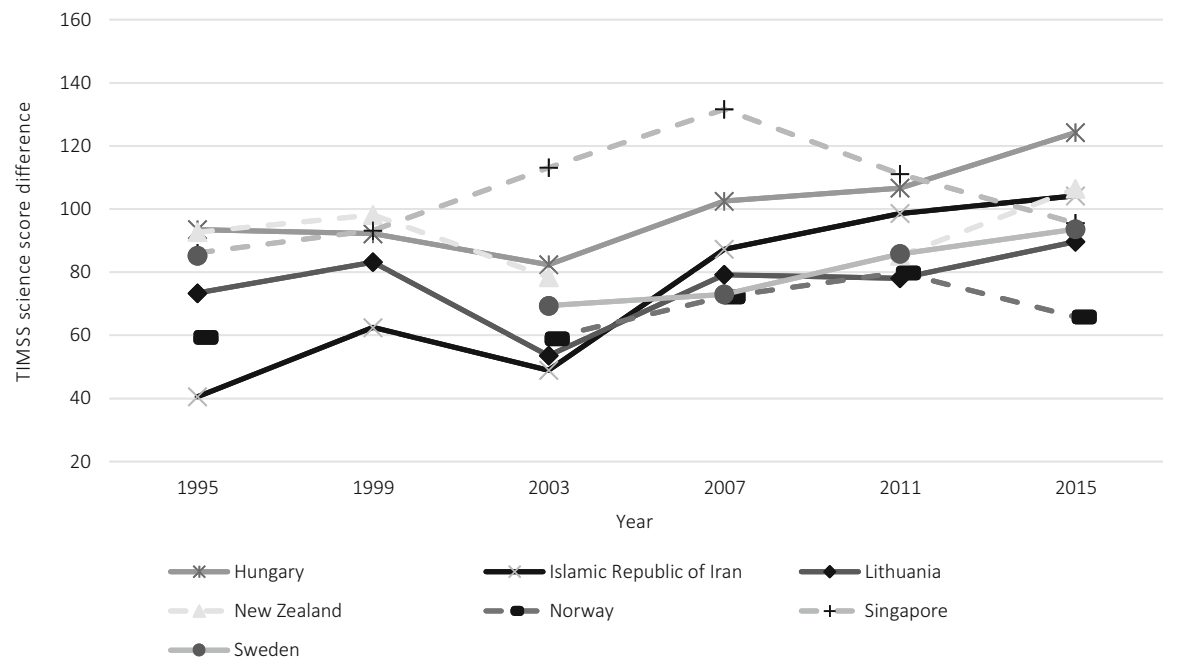

Fig. 4.2 Education systems showing an increasing science score difference between high- and low-SES* students over 20 years of TIMSS

Correspondingly, we found that among the six education systems that recorded an overall decrease in the SES* gap for science achievement (Fig. 4.4), the decrease was only significant for the United States. The mean score difference in science between high- and low-SES* students in the United States was 105 points in 1995 and 82 points in 2015 , indicating that the achievement gap in science has been narrowing over time. 


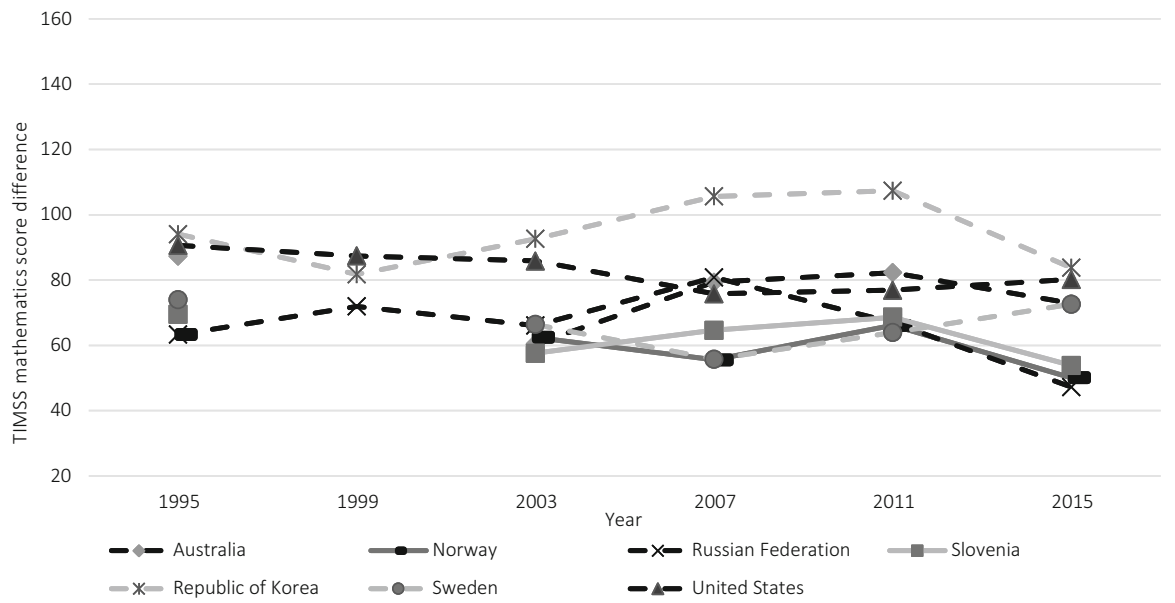

Fig. 4.3 Education systems showing a decreasing mathematics score difference between high- and low-SES* students over 20 years of TIMSS

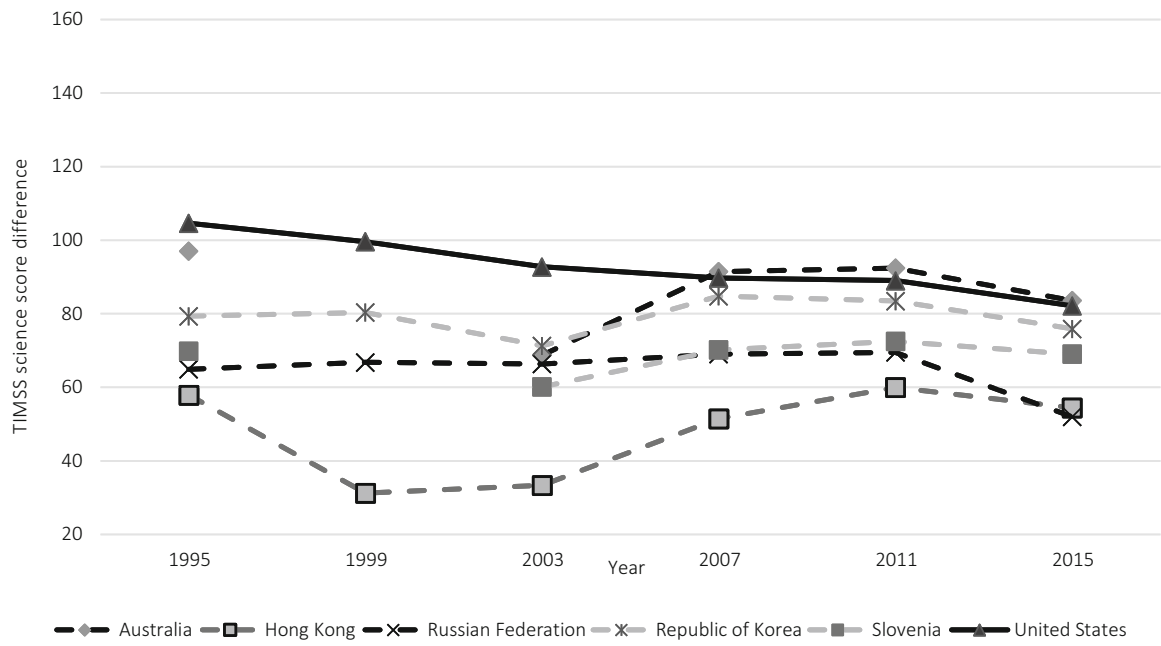

Fig. 4.4 Education systems showing a decreasing science score difference between high- and lowSES* students over 20 years of TIMSS

\subsection{Education System Specific Findings}

\subsubsection{Australia}

Australia has a decentralized education system, and responsibilities are held primarily by the states and territories. Australia offers a 10-year compulsory education for all children. The system is structured as seven or eight years of 
primary school, including kindergarten through to grade six or seven. Lower secondary school runs for three or four years, and upper secondary education comprises two years, from grade 11-12. Public schools are fully funded by the government, while private schools are partially funded by the government and also charge fees (Australian Government 2018).

Australian students have participated in every cycle of TIMSS since its inception in 1995. The average mathematics and science performance of Australian students has remained more or less the same over time. We categorized Australia as one of the countries that witnessed an overall decrease in the achievement gap between highand low-SES* students. However, a more precise description could be that the gap has not widened since 1995. For both mathematics and science, there was a substantial decrease in the gap between 1995 and 2003, by thereafter there was a considerable increase (Figs. 4.5 and 4.6). If we consider science scores, the achievement gap between high- and low-SES* students was 97 points in 1995 and 69 points in 2003. However, the gap increased to 91 points in 2007 and 92 points in 2011, before dropping again to 84 points in 2015. Overall, despite the clear increase since 2003, the gap in 2015 remains lower than it was in 1995. Note that our significance test results (Table 4.1) also show that the decrease in the SES* science achievement gap between 1995 and 2003 (28 points) and the increase between 2003 and 2015 (15 points) are statistically significant, while the difference between 1995 and 2015 (13 points) is not.

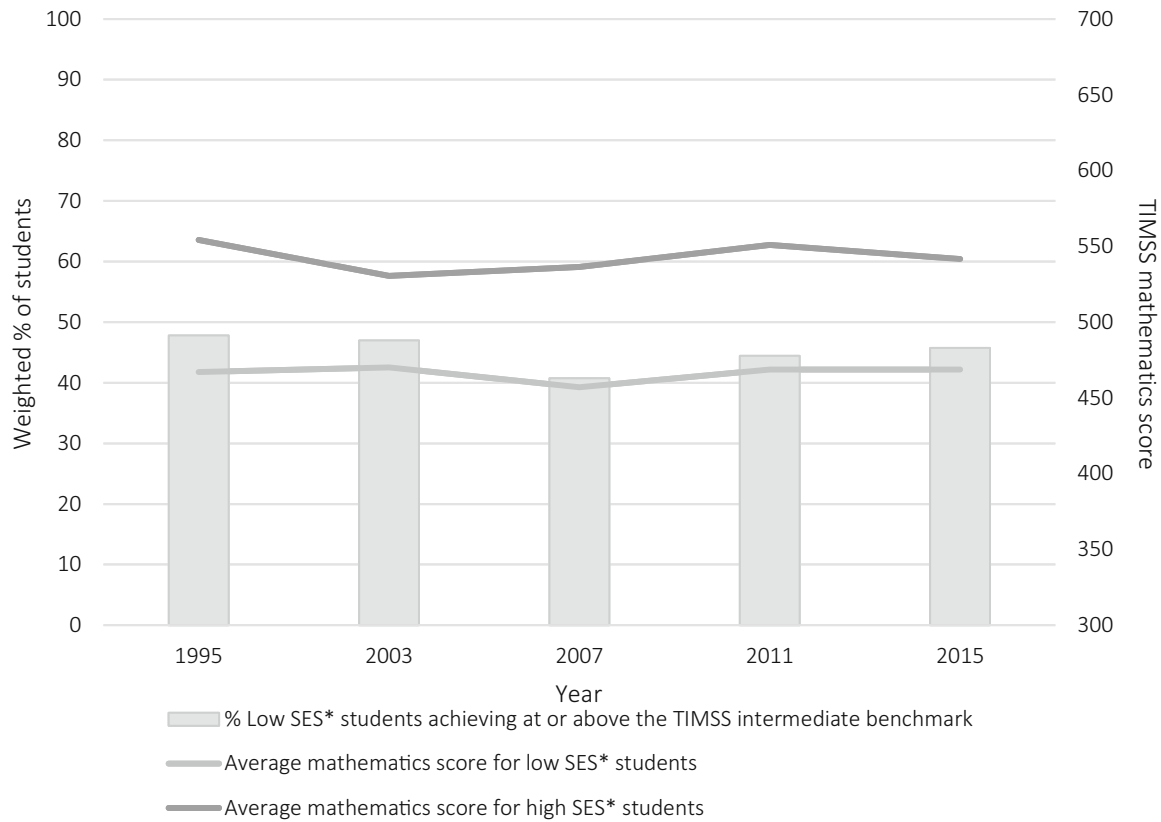

Fig. 4.5 Percentage of low-SES* students achieving at or above the TIMSS intermediate benchmark and the average mathematics score for low- and high-SES* groups for Australia (1995-2015) 


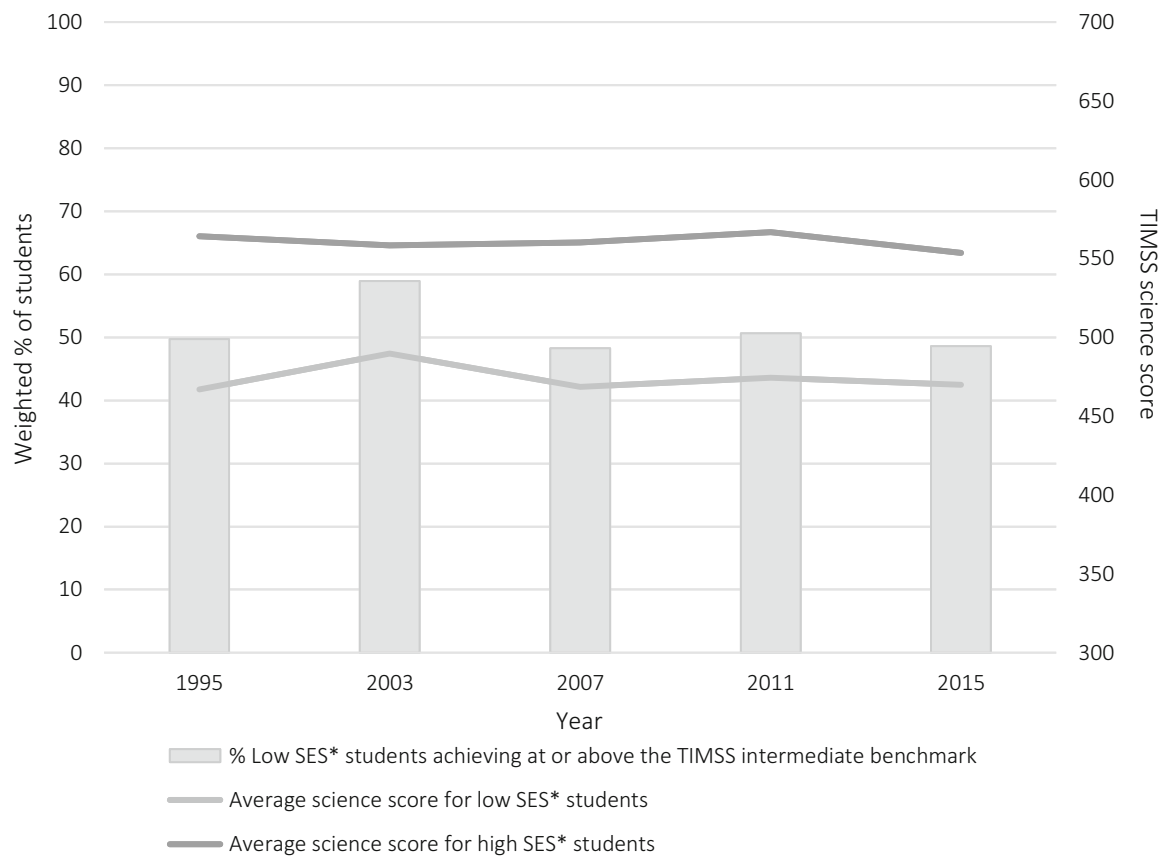

Fig. 4.6 Percentage of low-SES* students achieving at or above the TIMSS intermediate benchmark and the average science score for low- and high-SES* groups for Australia (1995-2015)

This pattern was also reflected by the percentage of low-SES* students achieving at or above the intermediate benchmarks in both mathematics and science in Australia. For example, in science, $50 \%$ of low-SES* students achieved at the intermediate benchmark in 1995 and the percentage increased to 59\% in 2003. However, after 2003, there was a noticeable decrease, and only about $50 \%$ of low-SES* students achieved at the intermediate benchmark across the last three cycles. In other words, Australia observed a significant decrease in educational inequality during the first decade of TIMSS, but this trend apparently reversed in the second decade.

More broadly, the gross domestic product (GDP) per person in Australia has been steadily increasing over the last two decades, from around US\$20,400 in 1995 to US\$ 56,400 in 2015. The percentage of Australian GDP spent on education has remained around 5\%. Furthermore, the Gini index (which assesses the level of inequality in the wealth of a nation; Gini 1921) for Australia remained at the 33-points level from 1995 to 2003, suggesting that there was no significant change in income inequality over that period. However, the Gini index increased to 35 in 2008 and remained at that higher level in 2010, suggesting a later increase in income inequality. This was also reflected by a stable increase in the top $10 \%$ of earners' share of pre-tax national income, which went from $27 \%$ in 1995 , to $29 \%$ in 2003, to $32 \%$ by 2015 . In summary, the country-level economic indicators seem to be in 
accordance with our findings, suggesting that Australia observed a strong, significant decrease in educational inequality during the first decade of TIMSS, but that this did not continue into the second decade.

\subsubsection{Hong Kong}

Hong Kong is one of the richest education systems in the world with a high GDP per person (OECD 2011), over US\$ 42,000 in 2015. During the period 1995-2015, the education system experienced many changes, especially after the transfer of its sovereignty from the United Kingdom to China in 1997. Until the 2009-2010 academic year, Hong Kong's education system was very similar to the British education systems. It subsequently changed to the Chinese system of six years of primary school, three years of junior (lower) secondary school, three years of senior (upper) secondary school, and four years of college. The government provides a free and universal education for the first 9 years of schooling to all children attending public schools. From the 2008-2009 academic year onwards, senior secondary education has also been free for all public school students (Hong Kong Education Bureau 2018).

Hong Kong have participated in every cycle of TIMSS since 1995 and their students have consistently achieved scores comparable with the top education systems in the TIMSS assessment. Our analyses show that students in Hong Kong performed remarkably well on the TIMSS mathematics and science assessments regardless of their SES* background. The average scores for low-SES* students for both mathematics and science are higher than the international intermediate benchmark in any given year (Figs. 4.7 and 4.8).

For both mathematics and science, the achievement gaps between high- and low-SES* students narrowed prior to 2003 but subsequently increased strongly. For example, the achievement gap in mathematics decreased from 53 points in 1995 to 35 points in 1999 , and 41 points in 2003 ; however, this was not a statistically significant decline (Table 4.1). The achievement gap widened to 64 points in 2007, 74 points in 2011, and 63 points in 2015. The 22-point increase from 2003 to 2015 is statistically significant (Table 4.1). As in Australia, there was a considerable decrease followed by a substantial increase. However, in contrast to Australia (where the later gaps never surpassed the gap in 1995), Hong Kong's subsequent increase in the SES* achievement gap in the second decade of TIMSS was much larger.

Moreover, for both mathematics and science, the percentage of low-SES* students achieving at or above the TIMSS intermediate benchmark indicate the same trends. As mentioned, low-SES* students in Hong Kong have performed remarkably well in international comparisons. This is reflected by the consistently high percentage of low-SES* students achieving at or above the intermediate benchmark in mathematics. In 1999 and 2003, 89\% of low-SES* students surpassed the benchmark, while only $79 \%$ did so in 2011; however, these percentages still surpass those of most other education systems. Hong Kong 


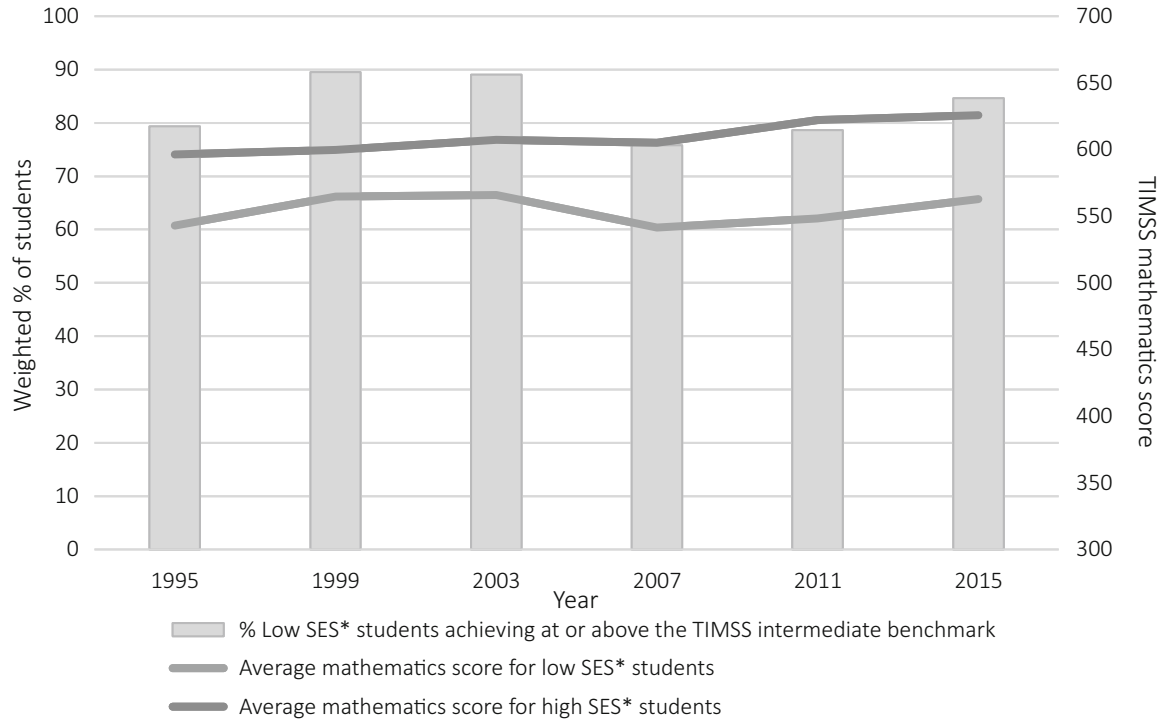

Fig. 4.7 Percentage of low-SES* students achieving at or above the TIMSS intermediate benchmark and the average mathematics score for low- and high-SES* groups for Hong Kong (1995-2015)

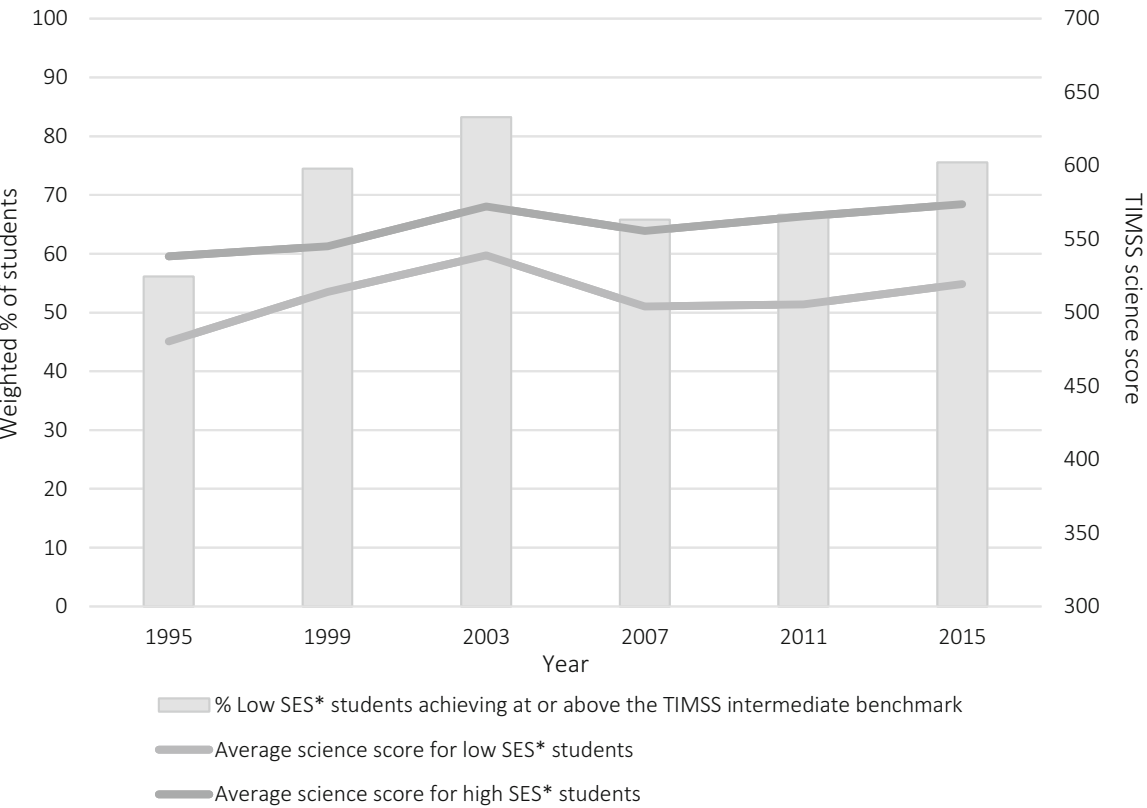

Fig. 4.8 Percentage of low-SES* students achieving at or above the TIMSS intermediate benchmark and the average science score for low- and high-SES* groups for Hong Kong (1995-2015) 
students, both from low- and high-SES* backgrounds, continued to perform very well, although there was evidence of a widening SES* achievement gap and growing educational inequality in the second decade of TIMSS.

One possible explanation may be related to macro-level changes in the Hong Kong economy. For example, the percentage of total government expenditure allocated to education increased from 17\% in 1996 to $23 \%$ in 2003, but dropped to $19 \%$ in 2015 . Similarly, GDP spending on education was $2.7 \%$ in 1995 , increased to $4.3 \%$ in 2003, and then dropped to $3.3 \%$ in 2015. Meanwhile, the Gini index was 43 in 1996 and 54 in 2011, suggesting increasing income inequality. In summary, the overall trend in income inequality mirrored the trend in educational inequality.

\subsubsection{Hungary}

Hungary has a decentralized education system with shared responsibilities among national, local, and institutional levels. Until age 18, students are mandated to receive compulsory education. For the years of compulsory education, public schools are offered free to all students while private schools charge fees. The education system in Hungary is structured as eight years of elementary education, followed by four years of secondary education. Secondary education typically covers grades $9-12$, and provides academic or vocational oriented programs.

Hungary has participated in every cycle of TIMSS since its inception in 1995. The average performance in mathematics and science among Hungarian grade eight students has been declining over time (Mullis et al. 2016). However, we found that Hungary also experienced a very strong increase in the achievement gap between students from high- and low-SES* groups. There was a 31-point increase in the gap in science (from 93 in 1995 to 124 in 2015) and a 41-point increase in the gap in mathematics (from 103 in 1995 to 144 in 2015) over the 20 years of TIMSS (Tables 4.2 and 4.3). From 2003 to 2007, while Hungarian students' overall performance declined, note that the decrease was much more extensive for low-SES* students than for high-SES* students. For instance, in mathematics, there was a 28 -point decrease (from 484 to 456 ) for low-SES* students but only an eight-point decrease (from 580 to 572) for high-SES* students (Fig. 4.9). Meanwhile, from 2011 to 2015, the average mathematics score for high-SES* students increased significantly, while it remained the same for low-SES* students. The significance test results show that the minor change between 1995 and 2003 is not statistically significant while the 48-point increase in the achievement gap between 2003 and 2015 is statistically significant (Table 4.1).

In addition, the percentage of low-SES* students achieving at or above the mathematics and science TIMSS intermediate benchmark is in agreement with the achievement gap trend (Figs. 4.9 and 4.10). The percentage of low-SES* students achieving at or above the mathematics intermediate benchmark decreased significantly, from 51\% in 1995 to 34\% in 2015 (Fig. 4.9). Over the period 1995-2015, a decline in performance can be observed for all students in Hungary, 
but the decline was more substantial for low-SES* students, resulting in a higher inequality in educational outcomes.

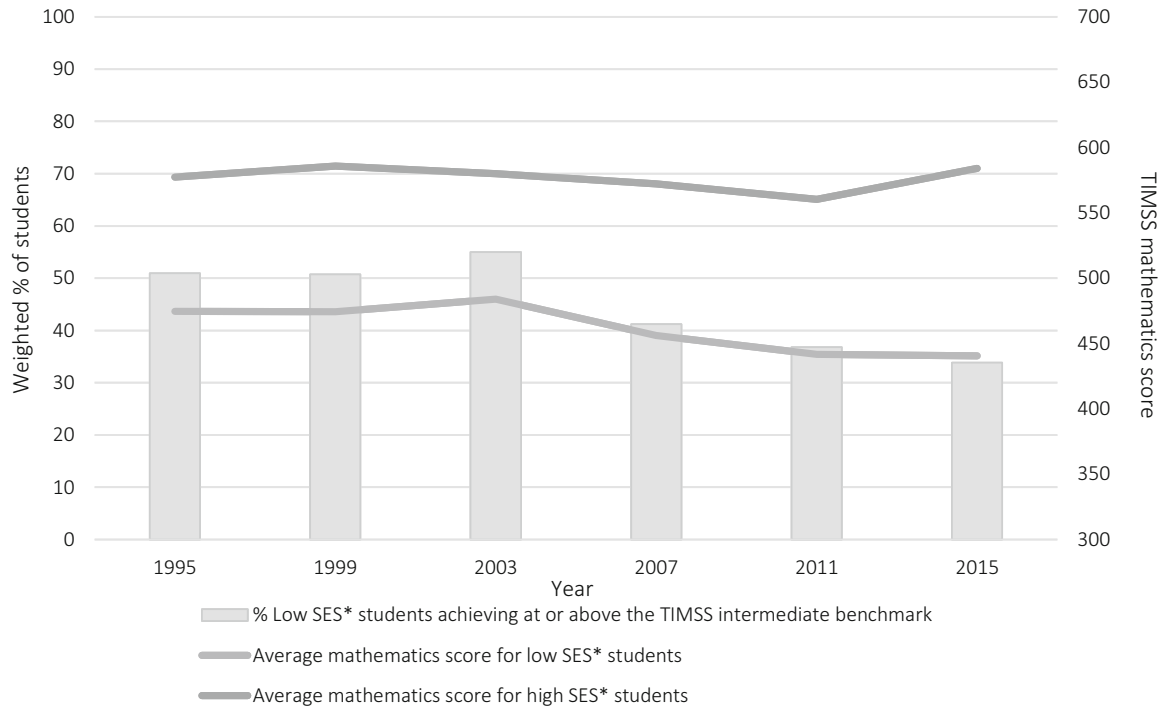

Fig. 4.9 Percentage of low-SES* students achieving at or above the TIMSS intermediate benchmark and the average mathematics score for low- and high-SES* groups for Hungary (1995-2015)

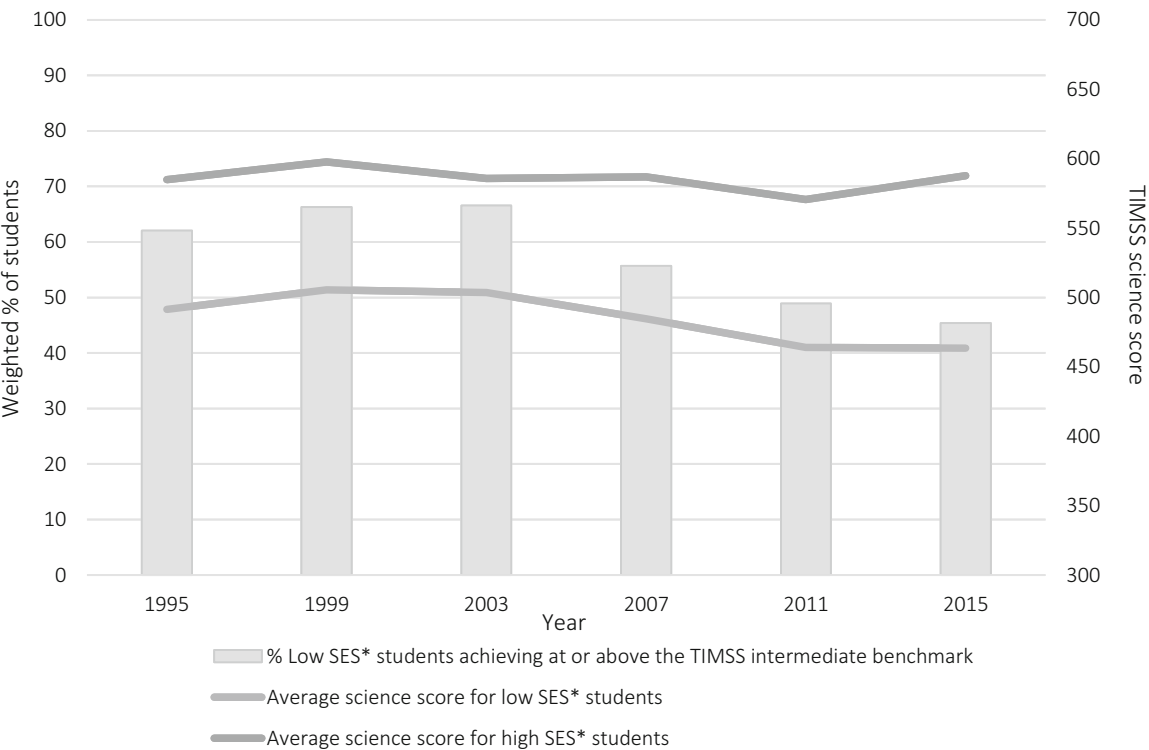

Fig. 4.10 Percentage of low-SES* students achieving at or above the TIMSS intermediate benchmark and the average science score for low- and high-SES* groups for Hungary (1995-2015) 
At the macro-level, Hungary has a relatively low GDP per person compared to other participating countries. By 2015, the current GDP per person for Hungary was a little over US\$12,000. The percentage of total government expenditure allocated to education was $10 \%$ in 1996 , increased to $12 \%$ in 2003 , and then dropped back to $9 \%$ in 2011 and 2014, which is considerably lower than in many other countries. These trends were also reflected in the percent of GDP spent on education, which was $4.9 \%$ in 1995, peaked at 5.8\% in 2003, and then dropped back to $4.7 \%$ in 2014 . Meanwhile, Hungary experienced a considerable increase in its Gini index from 28 in 1993 to 35 in 2005, suggesting a growing income inequality in its society. The increase in the Gini index is also supported by another indicator, which is the top $10 \%$ share of pre-tax national income. The available data from 1995 to 2008 shows that the top $10 \%$ of earners' share of national income increased strongly from $25 \%$ to $32 \%$. In summary, the evidence of growing income inequality in Hungary is in alignment with our findings suggesting that the achievement gap between high- and low-SES* students in Hungary has increased significantly over time.

\subsubsection{Islamic Republic of Iran}

Iran has a centralized education system where the Ministry of Education regulates all schools and holds financial responsibilities for primary and secondary education. The system is structured as five years of primary education, three years of secondary education (also called the "guidance cycle"), three years of upper secondary education, and one year of pre-university education or two years of associate degree education (Nuffic 2015). The 3 years of secondary education in the guidance cycle is used to differentiate whether a student best suited for an academic or vocational upper secondary education. Iran has participated in every cycle of TIMSS since 1995; TIMSS is administered to Iranian students at a critical time point in their education, immediately before they are separated into different tracks for their upper secondary education. Overall, the performance of Iranian students in mathematics and science has been below the international average. Of all the education systems we considered in this study, Iran is also the country with the lowest GDP per person.

The achievement gap, however, has been large and has significantly expanded over the 20 years of TIMSS. The mathematics score difference between high- and low-SES* students increased from 45 points in 1995, and 61 points in 2003, to 106 points in 2015 (Table 4.2). The significance test suggests that the 16-point increase between 1995 and 2003, and the 45-point increase between 2003 and 2015 are both statistically significant (Table 4.1). The average mathematics score for high-SES* students has been increasing over time, from 443 points in 1995 to 495 points in 2015, whereas the performance for low-SES* students has simultaneously been decreasing, from 398 points in 1995 to 388 points in 2015 (Fig. 4.11). These opposing trends suggest that the low-SES* students have been increasingly left behind, with SES* achievement gaps widening and educational inequality worsening. A similar trend is observed in science, with high-SES* students' performance remaining the same from 1995 to 2003, increasing significantly between 2003 and 2011, and decreasing slightly between 2011 and 2015 


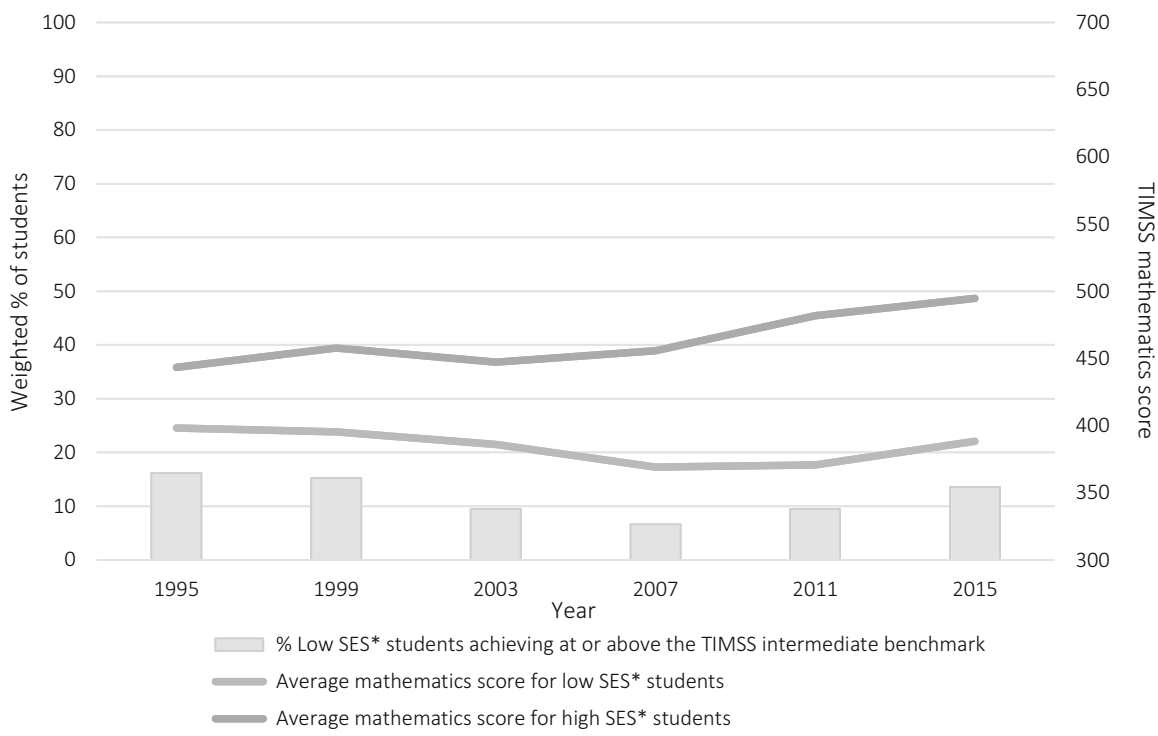

Fig. 4.11 Percentage of low-SES* students achieving at or above the TIMSS intermediate benchmark and the average mathematics score for low- and high-SES* groups for the Islamic Republic of Iran (1995-2015)

(Fig. 4.12). In contrast, low-SES* students' performance has been on a downward trajectory since 1995 .

Moreover, the percentage of low-SES* students achieving at or above the TIMSS intermediate benchmark reinforces the same story of declining performance among students in the bottom SES* quartile. In 1995, only $16 \%$ of students achieved at or above the benchmark in mathematics, with that number dropping to less than $10 \%$ in 2003, 2007, and 2011 (Fig. 4.11). For science, the percentage of low-SES* students achieving at or above the TIMSS intermediate benchmark dropped from $32 \%$ in 1995 to $19 \%$ in 2015 (Fig. 4.12). The strong decline in the percentage of low-SES* students achieving at or above the TIMSS intermediate benchmark supports our observation of a widening SES* achievement gap in Iran.

At the macro-level, Iran's economy has been negatively influenced by international sanctions and regional tensions since the 1980s. The GDP per person has increased, from US\$ 1592 in 1995 to US\$ 7729 in 2011, but this was accompanied by a significant decline to US\$ 4862 in 2015. The percentage of total government expenditure allocated to education increased from $15 \%$ in 1995 to $22 \%$ in 2003 ; this has subsequently decreased, and was $17 \%$ at its lowest point in 2012. In contrast, the percentage of GDP spent on education has continuously decreased from $4.4 \%$ in 1995 to $3 \%$ in 2014. Finally, the Gini index has remained high from 1994 to 2016, with one of its lowest points occurring at 39 in 2016. In summary, Iran has been spending less on education and retained a high Gini index, which suggests large income inequalities. This also supports our findings of an increasing achievement gap, with low SES* students steadily falling behind since 1995. 


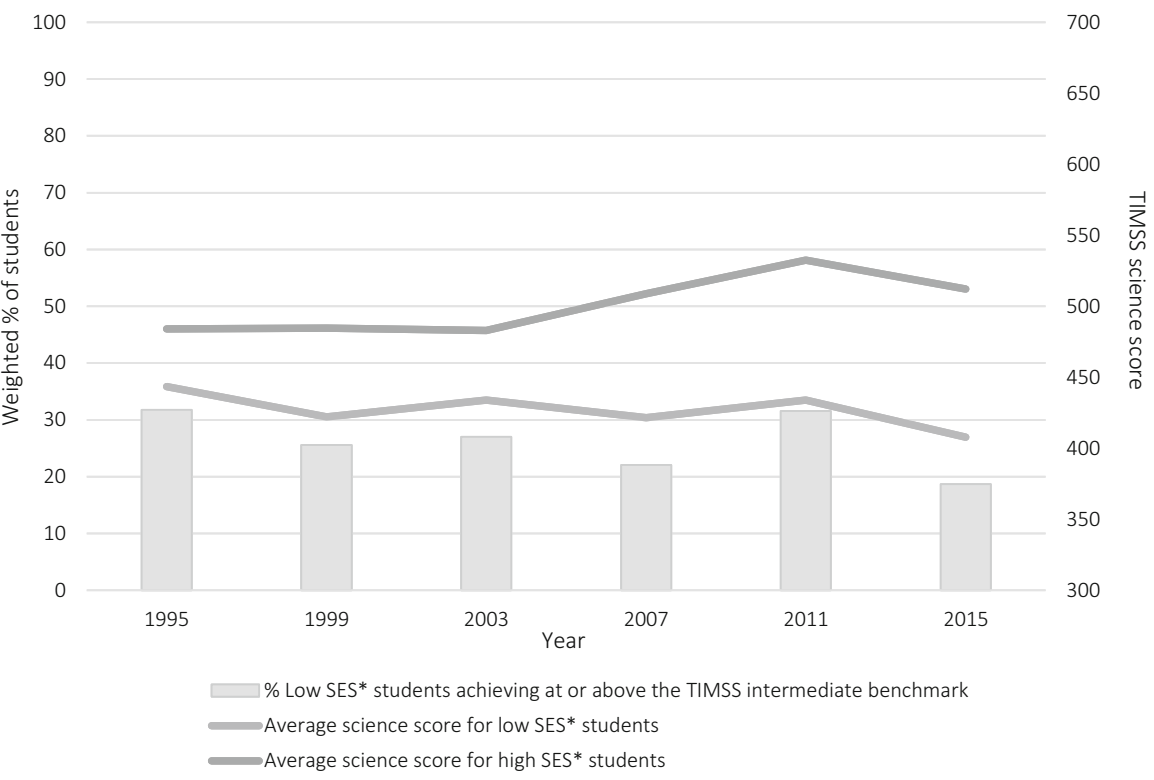

Fig. 4.12 Percentage of low-SES* students achieving at or above the TIMSS intermediate benchmark and the average science score for low- and high-SES* groups for the Islamic Republic of Iran (1995-2015)

\subsubsection{The Republic of Korea}

The Republic of Korea has a decentralized education system in which the local authorities play a significant role in planning the budget and making decisions. The school system comprises six years of primary school, three years of middle school, three years of high school, and four years of university. It offers nine years of free and compulsory education and implements a randomized school assignment system at the primary- and middle-school level within each school district (Lee 2001).

The Republic of Korea has participated in every cycle of TIMSS since 1995 and has performed among the top education systems in both the mathematics and science assessments. Similar to their peers in Hong Kong, students in the bottom SES* quartile in the Republic of Korea have also demonstrated a comparatively high achievement. The average mathematics score for low-SES* students was close to or even exceeded the TIMSS high-performing benchmark (550 points). However, the SES* achievement gap is still striking, considering the education system's generally high performance.

In terms of mathematics achievement, the gap between high- and low-SES* students remained almost unchanged in the first decade of TIMSS, going from 94 points in 1995, and 82 points in 1999, to 93 points in 2003. In the second decade of TIMSS, the achievement gap increased to 106 points in 2007 and 107 points in 2011. Although the achievement gap subsequently declined to 


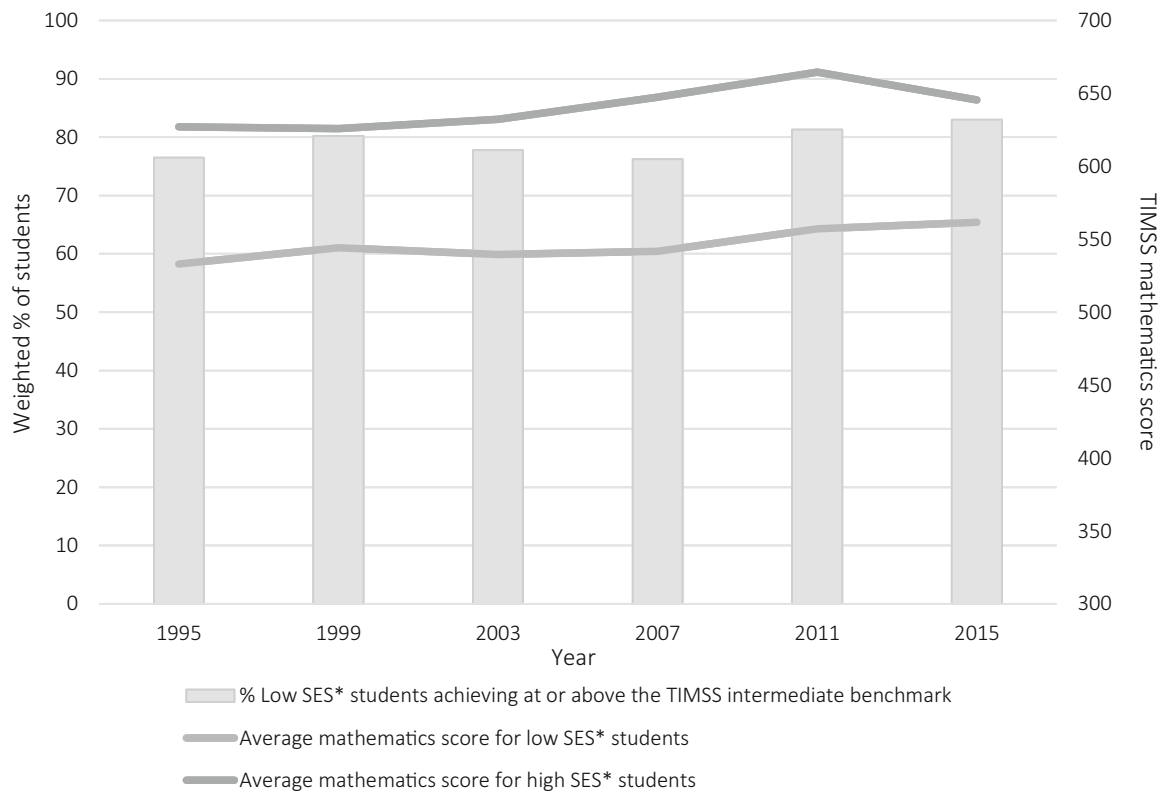

Fig. 4.13 Percentage of low SES* students achieving at or above the TIMSS intermediate benchmark and the average mathematics score for low- and high-SES* groups for the Republic of Korea (1995-2015)

84 points in 2015 , this was not due to an improvement in the performance of low-SES* students, but rather a decline in the achievement of high-SES* students (Fig. 4.13). Similarly, very minor changes were found in the science achievement gap (Fig. 4.14); in 2015, again the achievement gap closed slightly as the performance of high-SES* students had declined. However, we found that the change in the science achievement gap was not statistically significant (Table 4.1).

Furthermore, the bar graphs confirm that the changes in the mathematics and science achievement gaps in 2015 were mainly due to a decrease in high-SES* students' performance since the percentage of low-SES* students achieving at the TIMSS intermediate benchmark remained the same. Everything considered, Korean students on average have performed very well on the TIMSS assessment, but the SES* achievement gap is still sizable.

At the macro-level, the Republic of Korea experienced long-term stable economic development, with GDP per person increasing from US\$ 12,333 in 1995 to US\$ 27,105 in 2015, except for the significant decline around the time of the 1998 economic crisis. The government has also expanded support for education by spending more GDP on education over time. In 1995, only $3 \%$ of GDP was spent on education, but this had increased to $4.9 \%$ by 2011 . However, income inequality has widened over time, as reflected by the top $10 \%$ of earners' share of the national income, which increased from 29\% in 1995 to $44 \%$ in 2011. This accords with the increasing students' SES* achievement gap that we identified from 20 years of 


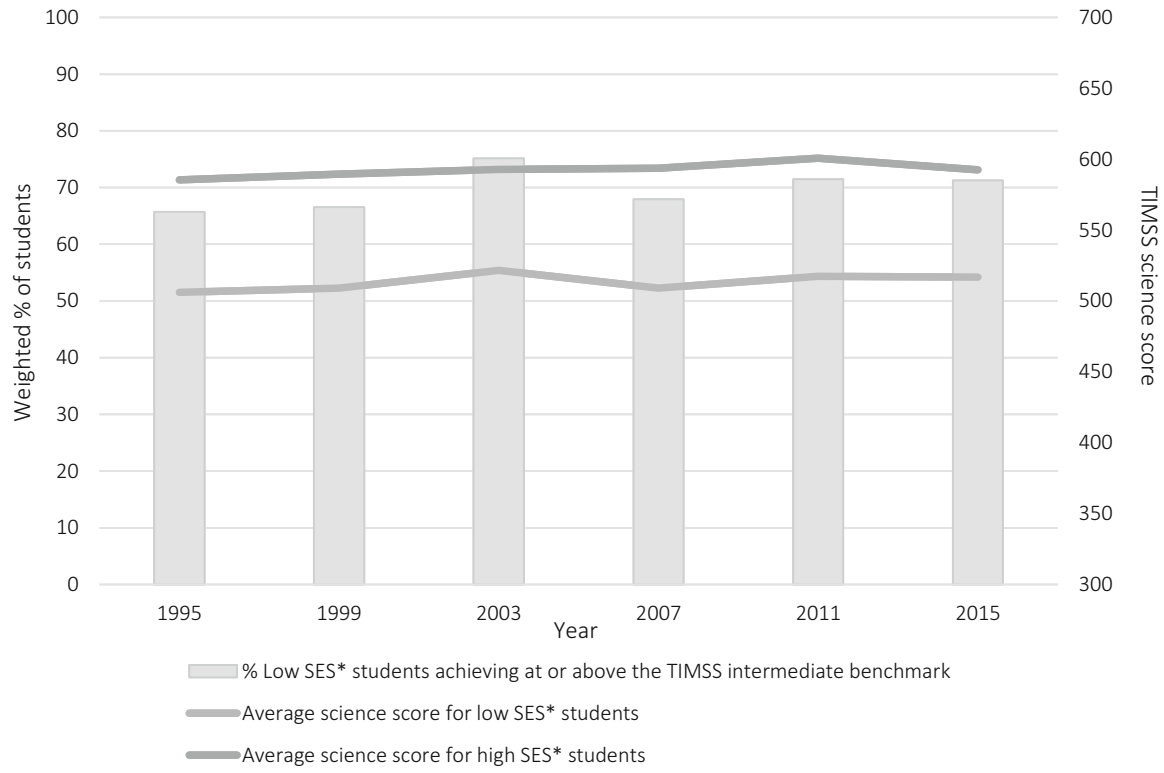

Fig. 4.14 Percentage of low-SES* students achieving at or above the TIMSS intermediate benchmark and the average science score for low- and high-SES* groups for the Republic of Korea (1995-2015)

TIMSS data. One possible link between the widening income gap and the increasing SES* achievement gap might be the private shadow education in the Republic of Korea, which is common practice for students and requires intensive parental involvement and financial support (Byun and Kim 2010).

\subsubsection{Lithuania}

Lithuania has established a decentralized education system, where school governance is distributed among state-, municipal-, and school-level authorities. Most schools are public schools, and offer a free and compulsory education for children between seven and 16 years of age. The Lithuanian education system consists of four years of primary education, six years of lower secondary education, and two years of upper secondary education (OECD 2017).

Lithuania has participated in every cycle of TIMSS from its inception in 1995. The average performance of Lithuanian students has increased by 40 points in mathematics and 58 points in science between 1995 and 2015, an improvement of about one-half of a standard deviation (100 points). Meanwhile, the increase in mathematics performance for high- and low-SES* students has remained essentially the same, suggesting the achievement gap has been stagnant (Fig. 4.15). 


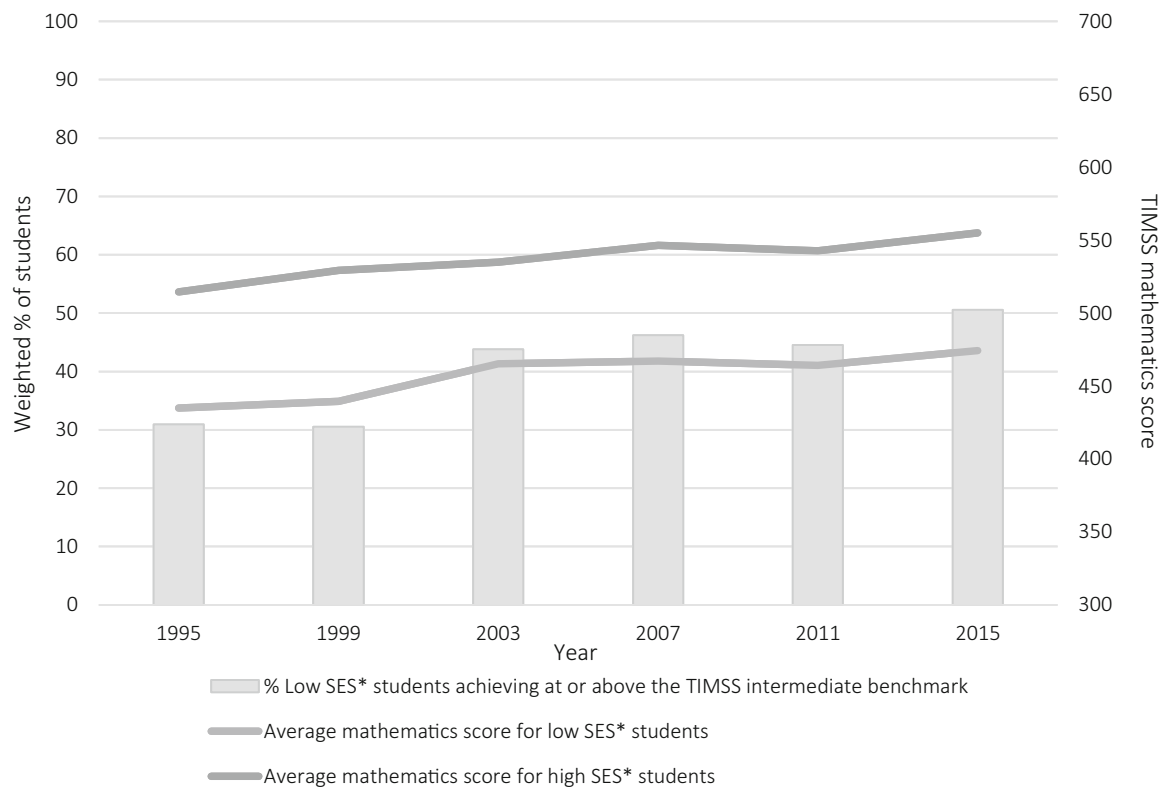

Fig. 4.15 Percentage of low-SES* students achieving at or above the TIMSS intermediate benchmark and the average mathematics score for low- and high-SES* groups for Lithuania (1995-2015)

The changes in mathematics performance were not statistically significant (Table 4.1). In contrast, the SES* achievement gap in science showed a different trend, decreasing from 73 points in 1995 to 54 points in 2003, and then increasing to 90 points in 2015 (Fig. 4.16). This 20-point decrease in the first decade of TIMSS, as well as the subsequent 36-point increase were both statistically significant, which resulted in an overall widening achievement gap between 1995 and 2015 (Table 4.1).

The percentage of low-SES* students achieving at or above the TIMSS mathematics and science intermediate benchmark deliver a more positive message. Note that only about $30 \%$ of students in Lithuania achieved at or above the TIMSS intermediate benchmark in mathematics in the first two cycles of the TIMSS assessment, while almost 50\% performed at or above the benchmark in 2015 (Fig. 4.15). Similarly, 27\% of low SES* students achieved at or above TIMSS intermediate benchmark in science in 1995, with that figure almost doubling in 2015 to 53\% (Fig. 4.16). Although the SES* achievement gap increased in the second decade of TIMSS, increasing numbers of students at the lowest SES* quartile have been reaching the intermediate benchmark over time.

More broadly, Lithuania has experienced a strong economic improvement since 1995, with GDP per person increasing from US\$ 2169 in 1995 to US\$ 14,289 in 2015. Meanwhile, the government has been spending less on education as a share of the total government expenditure over time: in 1995, $21 \%$ of the government's total expenditure was spent on education, while this decreased to $16 \%$ in 2003 , 


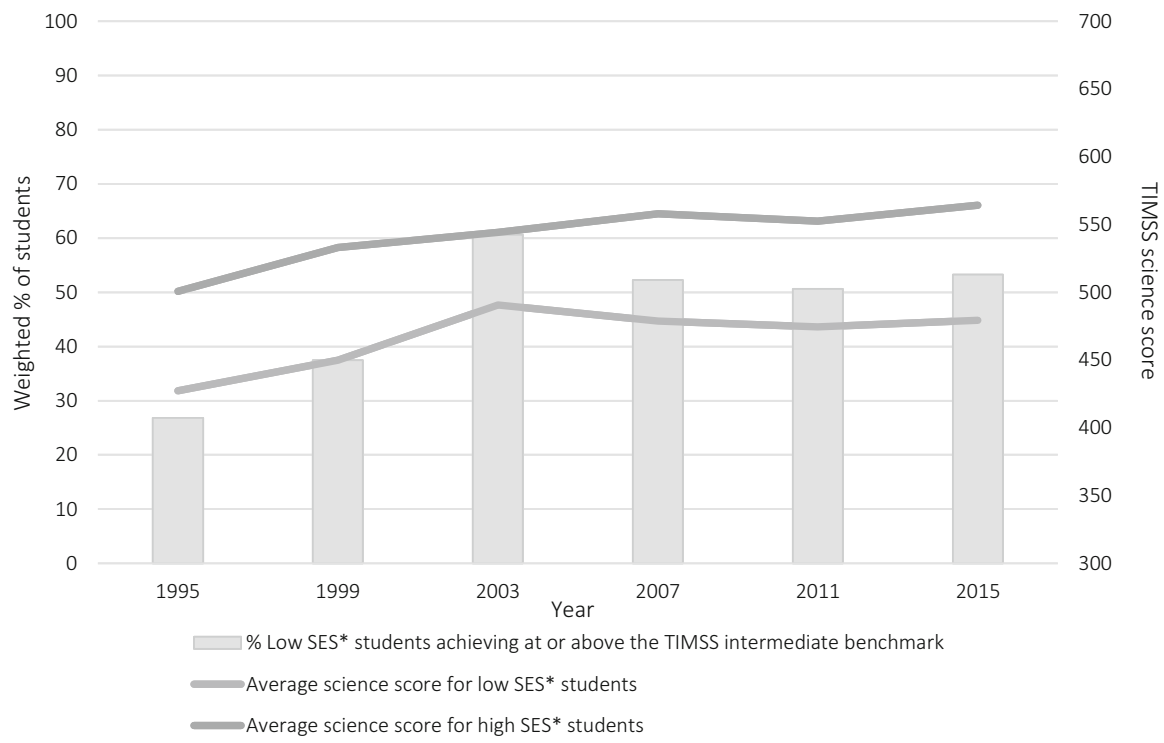

Fig. 4.16 Percentage of low-SES* students achieving at or above the TIMSS intermediate benchmark and the average science score for low- and high-SES* groups for Lithuania (1995-2015)

and continued to drop to $13 \%$ in 2013 . In addition, the Gini index in Lithuania increased from 34 in 1993 to 38 in 2014, indicating widening income inequality over time. This is in alignment with our finding that there is a noticeable increase in the SES* achievement gap for both mathematics and science between 2003 and 2015.

\subsubsection{New Zealand}

New Zealand has a decentralized education system with compulsory education for all children usually aged from five or six years to age 16 (grade 11). The four separate levels in the education system are early childhood, primary, secondary, and tertiary education. In New Zealand, authority for daily processes and financial management is decentralized from the government onto its educational institutions (Caygill and Flockton 2016). New Zealand has participated in most cycles of TIMSS since 1995, with the exception of the 2007 cycle. Over time, students have been improving their performance in both mathematics and science.

In New Zealand, the SES* achievement gap for mathematics declined in the first decade of TIMSS, but increased significantly after 2003 (Fig. 4.17). The achievement gap between high- and low-SES* students in mathematics was 82 points in 1995, and had decreased to 70 points by 2003. This 12-point change, however, was not statistically significant (Table 4.1). After 2003, the achievement gap increased to 78 points in 2011, and eventually reached 96 points in 2015 . The 


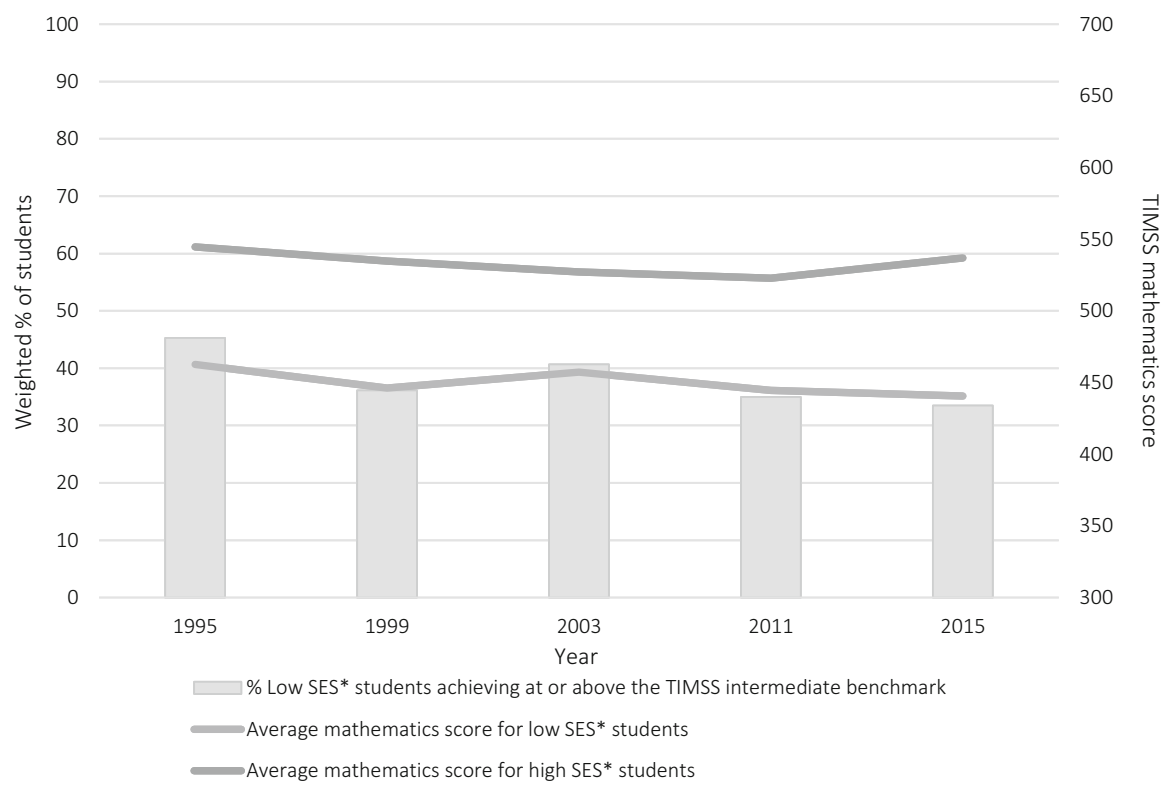

Fig. 4.17 Percentage of low-SES* students achieving at or above the TIMSS intermediate benchmark and the average mathematics score for low- and high-SES* groups for New Zealand (1995-2015)

26-point difference in the achievement of high- and low-SES* students between 2003 and 2015 was statistically significant (Table 4.1).

The SES* achievement gap in science performance experienced a corresponding ebb and flow (Fig. 4.18). It was 93 points in 1995 and dropped to 78 points by 2003 . In the second decade of TIMSS, however, the achievement gap increased to 85 points in 2011, and eventually reached 106 points in 2015, which was a statistically significant change (Table 4.1).

Furthermore, the percentage of low-SES* students achieving at or above the TIMSS intermediate benchmark for mathematics decreased over time, from $45 \%$ in 1995 , to $36 \%$ in 1999 , and $41 \%$ in 2003 . This then dropped to $35 \%$ in 2011 , and $34 \%$ in 2015. This suggests that the increasing achievement gap in the second decade was due to fewer low SES* students achieving at or above the TIMSS intermediate benchmark, as well as a strong improvement in high SES* students' performance.

In general, the GDP per person in New Zealand has been progressively increasing from US\$ 17,400 in 1995 to US\$ 38,202 in 2015. Similarly, annual government expenditure on education has been continuously growing, from almost $16 \%$ of the total government expenditure in 1995 to $18 \%$ in 2015. This concurs with the percentage of GDP spent on education, which has remained around six to seven percent, and is higher than the majority of other countries. The top $10 \%$ of earners' share of pre-tax national income in New Zealand has remained at 32\% over the past two decades, suggesting no significant change in income inequality. Future work should focus on other factors that might explain the increasing achievement. 


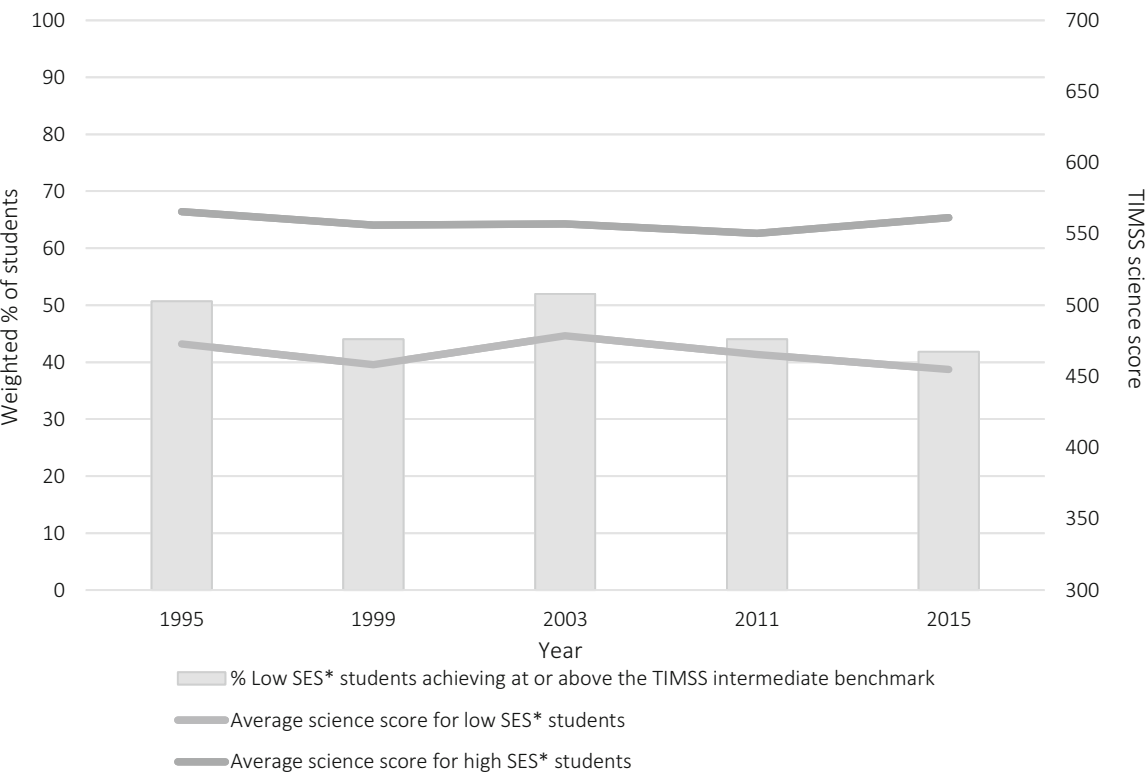

Fig. 4.18 Percentage of low-SES* students achieving at or above the TIMSS intermediate benchmark and the average science score for low- and high-SES* groups for New Zealand (1995-2015)

\subsubsection{Norway}

Norway offers a centralized education curriculum for grades one to 13 in all subjects. Access to public education is free for all students. Compulsory education usually starts at age six years and continues to age 15 or 16 years old. Most students in Norway are enrolled in publicly funded schools. There are three stages in the Norwegian education system. First is the "child stage," comprised of grades one to seven. Then there is the "youth stage," comprised of grades eight to 10 (Norwegian Directorate for Education and Training 2014), followed by a non-compulsory upper secondary school stage (grades 11-13). Sometimes, due to Norway's dispersed population, these stages may be either all delivered by one school or taught in schools separated by these stages.

Norway has participated in most cycles of TIMSS since 1995, with the exception of the 1999 cycle. Norway observed an overall decrease in the achievement gap for mathematics between high- and low-SES* students over time. More specifically, there was no significant change in the gap between 1995 and 2003. After 2003, the gap decreased from 63 points to 56 points in 2007, and 50 points in 2015, with an intermediate increase in 2011 (Fig. 4.19). Despite this minor volatility in the trend, we consider there to be an overall decreasing trend over the time period 1995 to 2015 because, in 2015, the gap reached its lowest point. Our results showed that the observed 13 point-decrease was statistically significant (Table 4.1). 


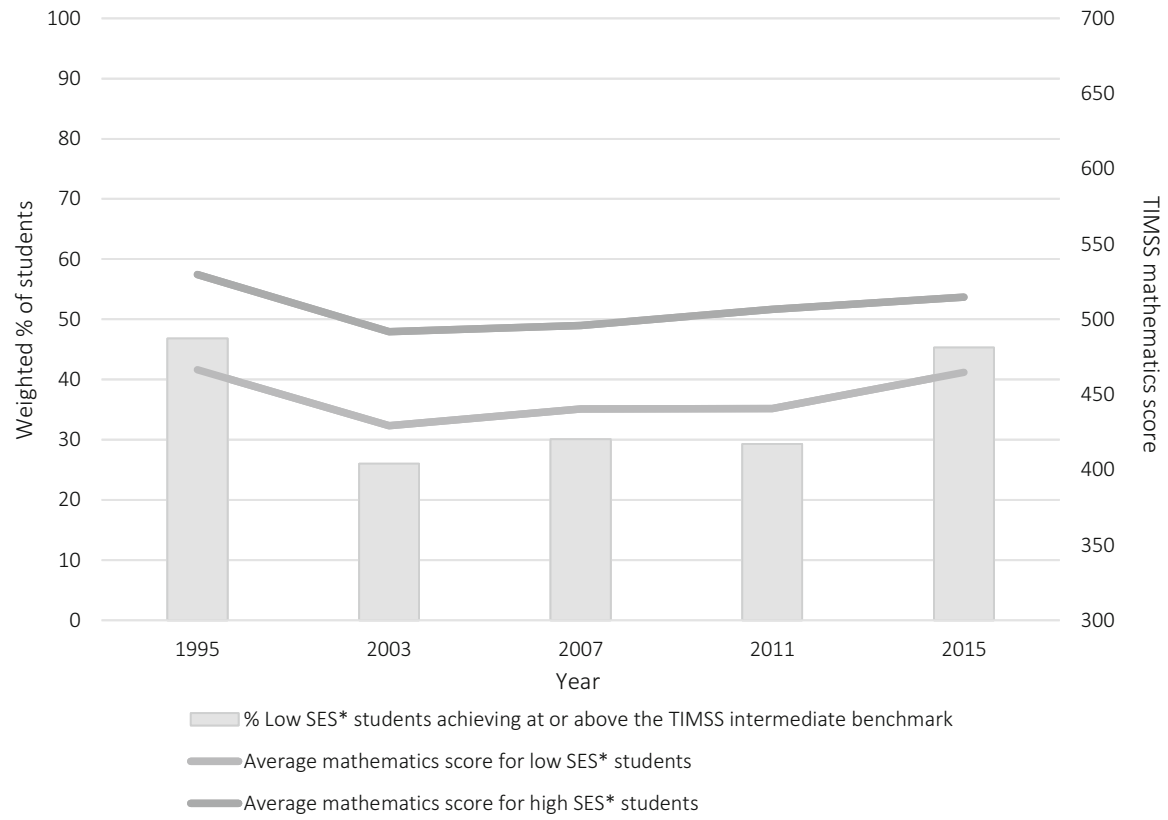

Fig. 4.19 Percentage of low-SES* students achieving at or above the TIMSS intermediate benchmark and the average mathematics score for low- and high-SES* groups for Norway (1995-2015)

The change in the percentage of low-SES* students achieving at or above the TIMSS mathematics intermediate benchmark provides more information about the trend. For example, the achievement gap remained the same from 1995 to 2003. However, in 2003, fewer low-SES* students achieved at or above the TIMSS intermediate benchmark than in 1995, due to an overall decline in mathematics performance for all students in Norway. In contrast, the decline in the gap in 2015 between high- and low-SES* students is due more to improvement in low-SES* students' performance than high-SES* students' performance.

Conversely, for science, the SES* achievement gap is not statistically significant and remained essentially the same (about 60 points) between 1995 and 2003 (Fig. 4.20). There was then a considerable increase to 72 points in 2007 , and 80 points in 2011, followed by a sizable decline to 66 points in 2015. The difference in the gaps between 1995 and 2015, and 2003 to 2015 were not statistically significant (Table 4.1).

As in mathematics, there was no change in the SES* achievement gap in science between 1995 and 2003, due to an overall decline in performance for all students in Norway. The increase in the achievement gap in 2007 occurred because of a decline in low-SES* students' performance, with less than $40 \%$ of low-SES* students achieving at or above the TIMSS intermediate benchmark in 2007, while high-SES* students' performance remained the same. Moreover, between 2007 and 2011, low-SES* students' performance in science did not improve as much as that of 




Fig. 4.20 Percentage of low-SES* students achieving at or above the TIMSS intermediate benchmark and the average science score for low- and high-SES* groups for Norway (1995-2015)

high-SES* students. The percentage of low-SES* students whose achievement was at or above the TIMSS intermediate benchmark remained the same. Therefore, the observed widening of the SES* achievement gap from 2007 to 2011 was due mainly to an improvement in high-SES* students' performance. After that, the gap declined from 2011 to 2015 because of a decline in high-SES* students' performance and a slight increase in low-SES* students' performance.

By and large, the GDP per person in Norway has been gradually increasing over the last two decades, from US\$ 34,875 in 1995 to US\$ 74,498 in 2015. The share of total government expenditure spent on education remained the same, at $17 \%$ of the total government expenditure in 1995 and 2013. This is in agreement with the percentage of GDP spent on education, which has also remained constant at around $7 \%$, a figure that is significantly higher than most of its international counterparts. Additionally, in the second decade of TIMSS, the Gini index for Norway suggested a significant decline in income inequality, decreasing from 32 in 2004 to 27 in 2014. This is partially consistent with our finding that there was a significant decrease in the SES* achievement gap in mathematics.

\subsubsection{Russian Federation}

The Russian Federation provides 11 years of compulsory education for all children, usually from the age of six-and-a-half years up to age 16. Grade one is the first year 
of compulsory education, while grade 11 is the last year of secondary education and compulsory schooling. Primary education comprises grades one to four, lower secondary education includes grades five to nine, and upper secondary education consists of grades 10 and 11. From 2000, the Russian government commenced its development of a new educational reform program, with an aim to provide higher quality education, as well as more equal access (Kovaleva and Krasnianskaia 2008). Overall, in terms of policymaking and funding, the Russian education system has become more decentralized, with federal education authorities responsible for developing and overseeing federal/educational standards, policy, and legislation, as well as those of federal subjects (republics).

The Russian Federation has participated in every cycle of the TIMSS assessment. The Russian Federation can be categorized as one of the education systems that witnessed an overall decrease in the SES* achievement gap, although the difference in the gap between 1995 and 2015 is not statistically significant (Table 4.1). For mathematics, the SES* achievement gap remained the same between 1995 and 2003, and then significantly decreased between 2003 and 2015. The achievement gap between high- and low-SES* students in mathematics was 63 points in 1995 and 72 points in 1999, followed by a small decrease to 66 points in 2003 (Fig. 4.21). The gap increased to 81 points in 2007, then decreased again to 67 points in 2011, before falling further to 47 points in 2015 .

The trend is also reflected by the percentage of low-SES* students achieving at or above the TIMSS intermediate benchmark in the Russian Federation for mathematics in the first decade of TIMSS. The percentage of low-SES* students achieving at or above the TIMSS intermediate benchmark declined from 1995 to 2003. In 1995, 60\% of low-SES* students achieved at or above the TIMSS intermediate benchmark for mathematics, while this number declined to $57 \%$ in 1999 , and $49 \%$ in 2003 . The percentages increased to $50 \%$ of low-SES* students achieving at or above the TIMSS intermediate benchmark in 2007, 66\% in 2011, and 69\% in 2015, partially explaining the decreasing SES* achievement gap in the second decade of TIMSS.

For science, there appears to have been no noticeable change in the achievement gap for the first decade of TIMSS, and a substantial decrease is noted for the last two cycles of the TIMSS assessment (Fig. 4.22). There was also a decrease in the percentage of low-SES* students achieving at or above the TIMSS intermediate benchmark from 1995 to 2003. This suggests that the relatively consistent achievement gap from 1995 to 2003 was due to an overall decrease in both highand low-SES* students' performance. In the TIMSS cycles after 2003, an increasing percentage of low-SES* students achieved at or above the TIMSS intermediate benchmark, explaining the decreasing trend in the SES* achievement gap between 2003 and 2015.

GDP per person has been steadily increasing in the country over the last two decades from around US\$ 2700 in 1995 to US\$ 9329 in 2015. The percentage of GDP spent by government on education was low, at around three to four percent, indicating a relatively low level of investment in education compared with other education systems. However, the Gini index went from 46 in 1996 to 37 in 2002, suggesting that there was a significant reduction in income inequality during that period. This decline then reversed in 2007, when the Gini index increased to 42, but 
90

80

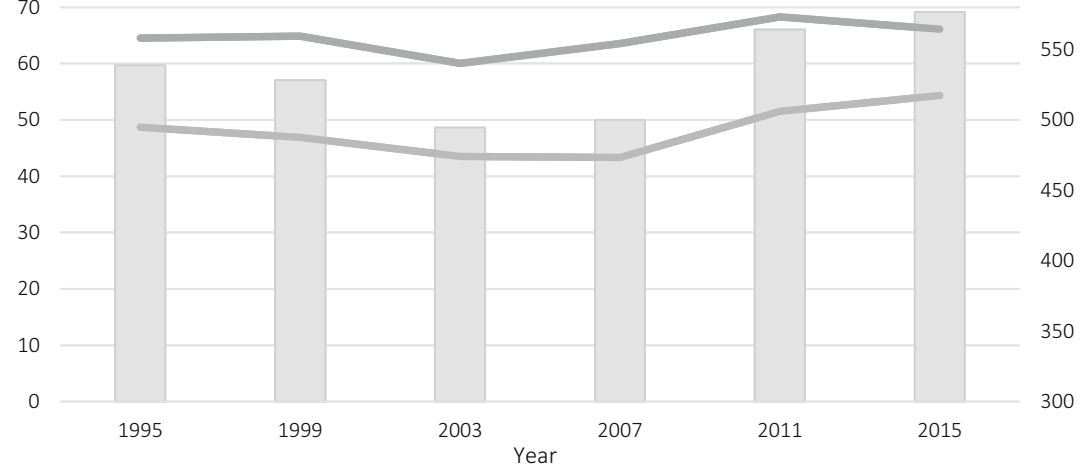

$\square$ Low SES* students achieving at or above the TIMSS intermediate benchmark

Average mathematics score for low SES* students

Average mathematics score for high SES* students

Fig. 4.21 Percentage of low-SES* students achieving at or above the TIMSS intermediate benchmark and the average mathematics score for low- and high-SES* groups for the Russian Federation (1995-2015)

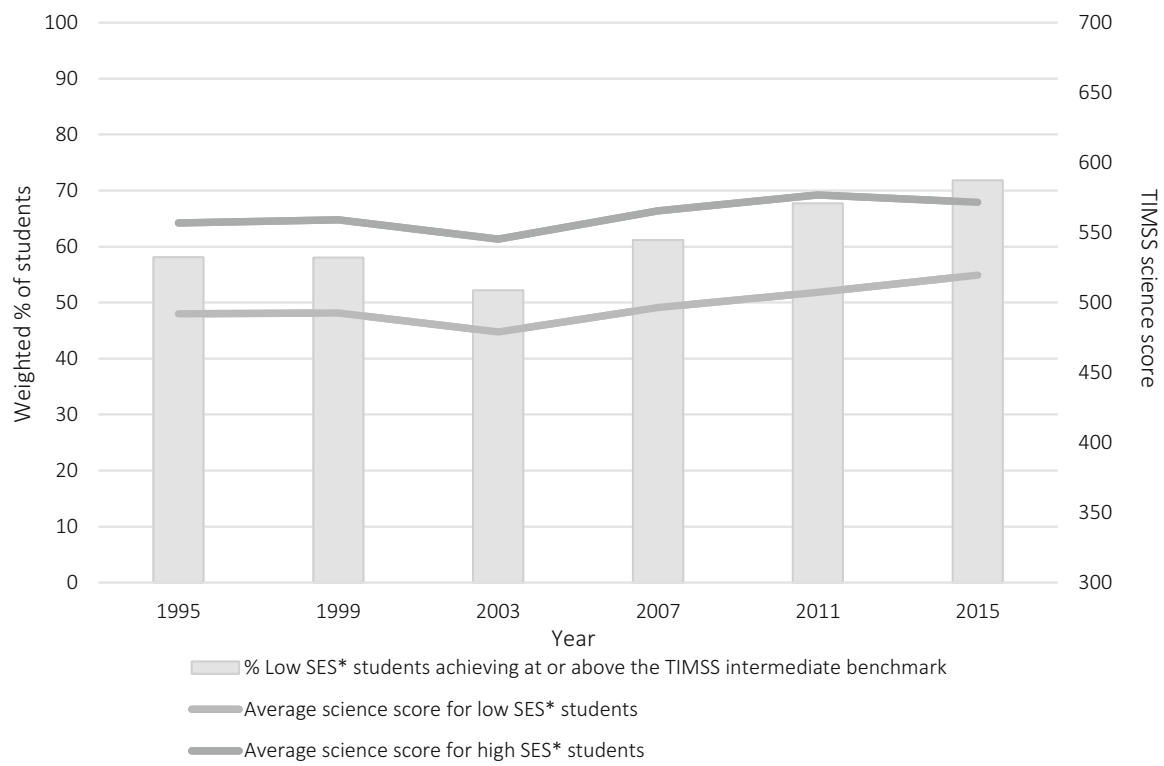

Fig. 4.22 Percentage of low-SES* students achieving at or above the TIMSS intermediate benchmark and the average science score for low- and high-SES* groups for the Russian Federation (1995-2015) 
by 2015 it had again dropped to 38 points. In conclusion, country-level indicators support our findings suggesting that the Russian Federation observed a non-significant change in the SES* achievement gap between 1995 and 2003, and a significant decrease thereafter. This was accompanied by a reduction in income inequality over the last 10 years.

\subsubsection{Singapore}

Singapore has a centralized education system and offers six years of compulsory education for all children. The Singaporean school system is structured by grade. Grades one to six are compulsory schooling. Although secondary education is not compulsory in Singapore, it is completed by almost every student. Grade 10 or 11 is the last year of secondary education (Ministry of Education, Singapore 2016). The majority of Singapore's students go to publicly funded schools.

Singapore has participated in every cycle of the TIMSS assessment from 1995 to 2015, and is consistently among the top performers in the TIMSS mathematics and science assessments. A very high percentage of Singaporean students in the bottom SES* quartile also achieved at or above the TIMSS intermediate benchmark in both mathematics and science. However, the achievement gap between high- and low-SES* students has remained large.

The SES* achievement gap increased from 1995 to 2003, and reached a peak in the 2007 cycle of TIMSS in both mathematics and science (Figs. 4.23 and 4.24). For example, the gap in mathematics was 48 points in 1995, 85 points in 2003, and 106 points in 2007 . The achievement gap for mathematics remained a little over 80 points during the second decade of TIMSS. Singapore clearly demonstrates a significantly widening achievement gap over 20 years of TIMSS. Significance test results also showed that the increase in the SES* achievement gap between 1995 and 2015 (37 points) was statistically significant (Table 4.1).

Moreover, changes in the percentage of low-SES* students achieving at or above the TIMSS intermediate benchmark indicated the same trend. As mentioned, low-SES* students in Singapore performed impressively well in this measure compared with students in most other education systems; this is reflected by a consistently high percentage of low-SES* students achieving at or above the TIMSS intermediate benchmarks. For example, in 1995, almost all students in the lowest SES* quartile achieved at or above the TIMSS intermediate benchmark for mathematics. However, by 2007, that number had declined substantially, even though it remained at a relatively high level of $74 \%$. It increased again to almost 85\% in 2011 and 2015, which, while higher than in most other education systems, was still lower than it was in 1995. In summary, despite the relatively high achievement of the low-SES* group, the achievement gap in Singapore has widened over the 20 years of TIMSS, and educational equality is lower than in 1995.

On a larger scale, GDP per person in Singapore has been increasing over the study period of 20 years, from around US\$ 25,000 in 1995 to US\$ 53,630 in 2015. In 


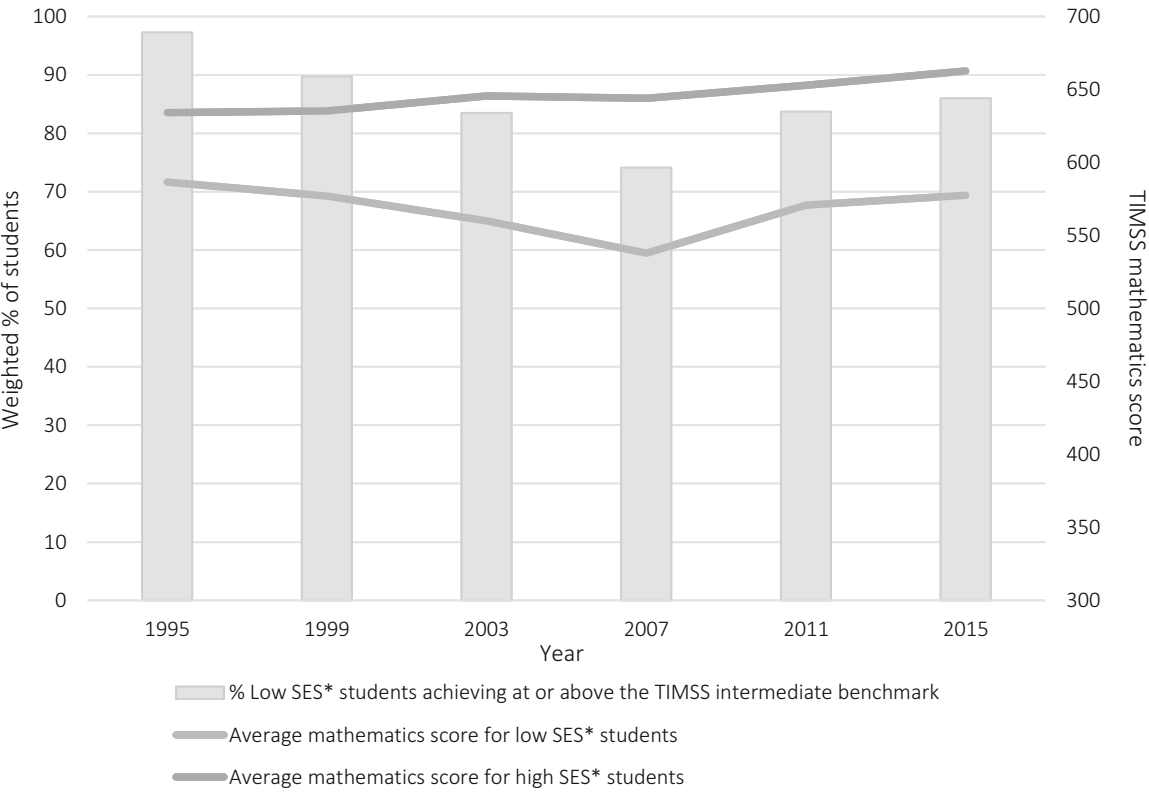

Fig. 4.23 Percentage of low-SES* students achieving at or above the TIMSS intermediate benchmark and the average mathematics score for low- and high-SES* groups for Singapore (1995-2015)

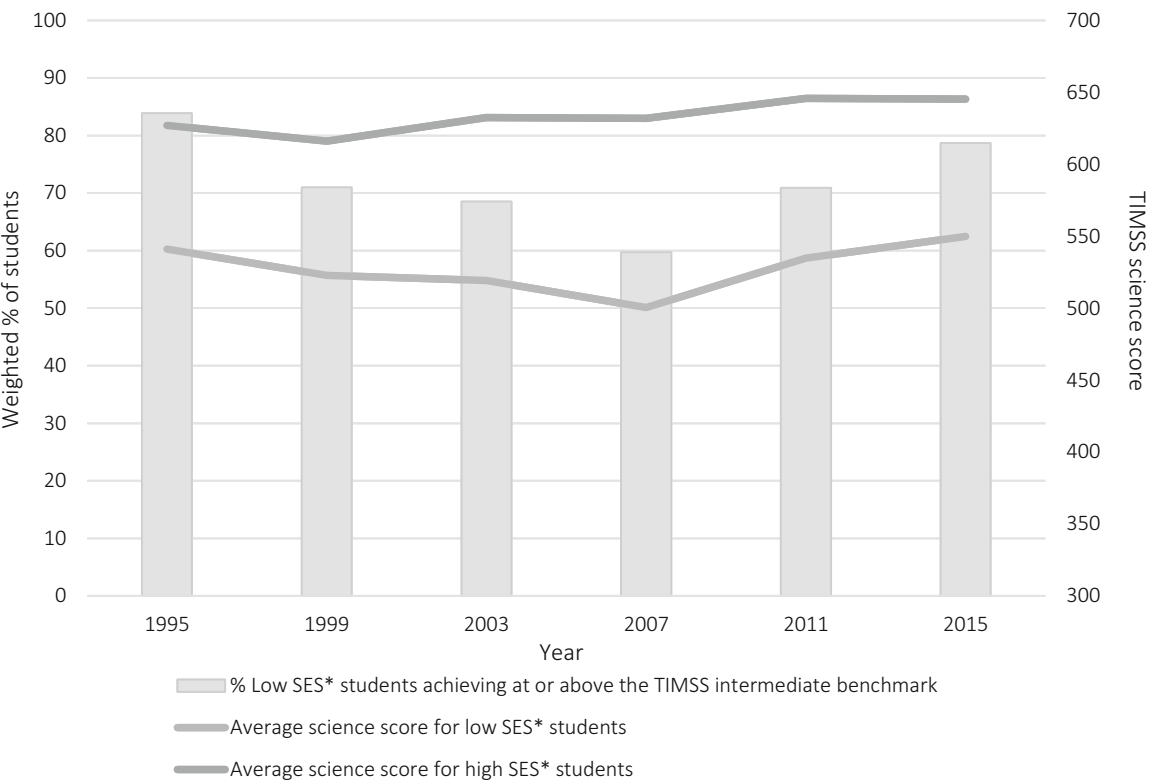

Fig. 4.24 Percentage of low-SES* students achieving at or above the TIMSS intermediate benchmark and the average science score for low- and high-SES* groups for Singapore (1995-2015) 
contrast, for most of the time, the percentage of total government expenditure devoted to education has remained at a constant level of around $20 \%$, with the lowest reported expenditure being $17 \%$ in 2010 . In terms of income inequality, the only available data from the Gini index was 42 in 1998 and 46 in 2015. In addition, a look at the top $10 \%$ of earners' share of national income in Singapore confirms the growing trend in inequality over the study period: this figure increased from $30 \%$ of the total in 1995 to almost $44 \%$ in 2014. All told, while achievement remains relatively high, there is evidence for increasing inequality in both income and education outcomes in Singapore, which supports our finding of a significant increase in SES* achievement gaps.

\subsubsection{Slovenia}

Slovenia distributes the governance of the education system between the central government and schools. The Slovenian school system is structured by grades; children start at grade one with nine years of compulsory education ending with grade nine. After compulsory basic education, the next stage is two to five years of non-compulsory upper secondary education with different types of general education and vocational and technical education (Ministry of Education, Science and Sport 2015).

Slovenia has participated in every TIMSS cycle since 1995 and its overall performance in mathematics and science has been above the international average. Slovenian students, regardless of their SES* background, achieved close to or above the TIMSS intermediate benchmark in both mathematics and science across 20 years of TIMSS (Figs. 4.25 and 4.26).

We categorized Slovenia as one of the countries that observed an overall significant decrease in the average mathematics score difference between highand low-SES* students. For both mathematics and science, there was a minor decrease in the achievement gap between 1995 and 2003 (Table 4.1). For instance, the decline in the achievement gap between high- and low-SES* students in mathematics between 1995 and 2003 was 10 points, a reduction from 69 points in 1995 to 58 points in 2003. Subsequent TIMSS cycles showed no further evidence of a decreasing trend, but the overall difference between 1995 and 2015 (14 points) was statistically significant.

As time progressed, comparatively more low-SES* students were achieving at or above the TIMSS intermediate benchmark. For example, in 1995, 41\% of low-SES* students achieved at or above the TIMSS intermediate benchmark, but this increased to $61 \%$ in 2015 . Therefore, the 14-point reduction in the SES* achievement gap between 1995 and 2015 was due to an improvement in low-SES* students' performance.

The GDP per person in Slovenia has been steadily growing over the study period from around US\$10,690 in 1995 to US\$20,873 in 2015. However, the percentage of total government expenditure allocated to education continuously decreased, from 
80

70

60

50

40

30

20

10

0

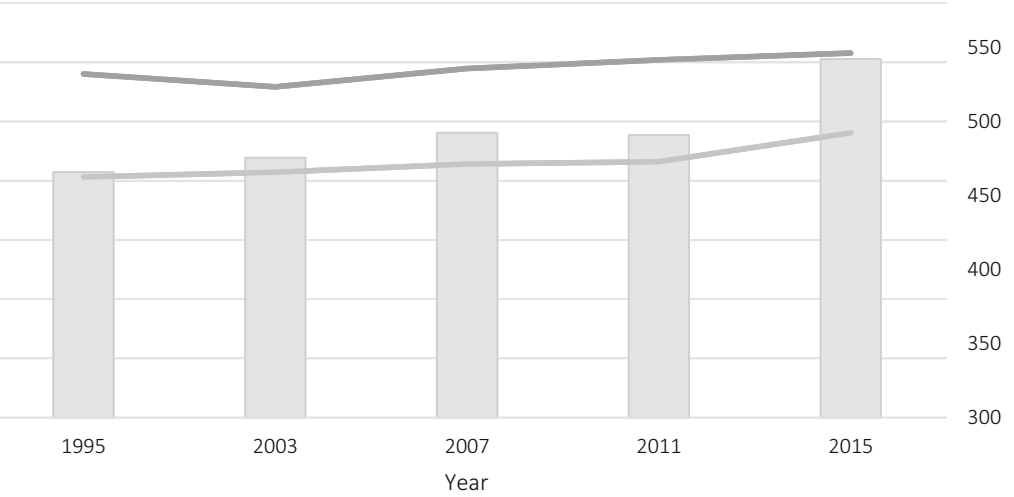

$\square$ Low SES* students achieving at or above the TIMSS intermediate benchmark

Average mathematics score for low SES* students

Average mathematics score for high SES* students

Fig. 4.25 Percentage of low-SES* students achieving at or above the TIMSS intermediate benchmark and the average mathematics score for low- and high-SES* groups for Slovenia (1995-2015)

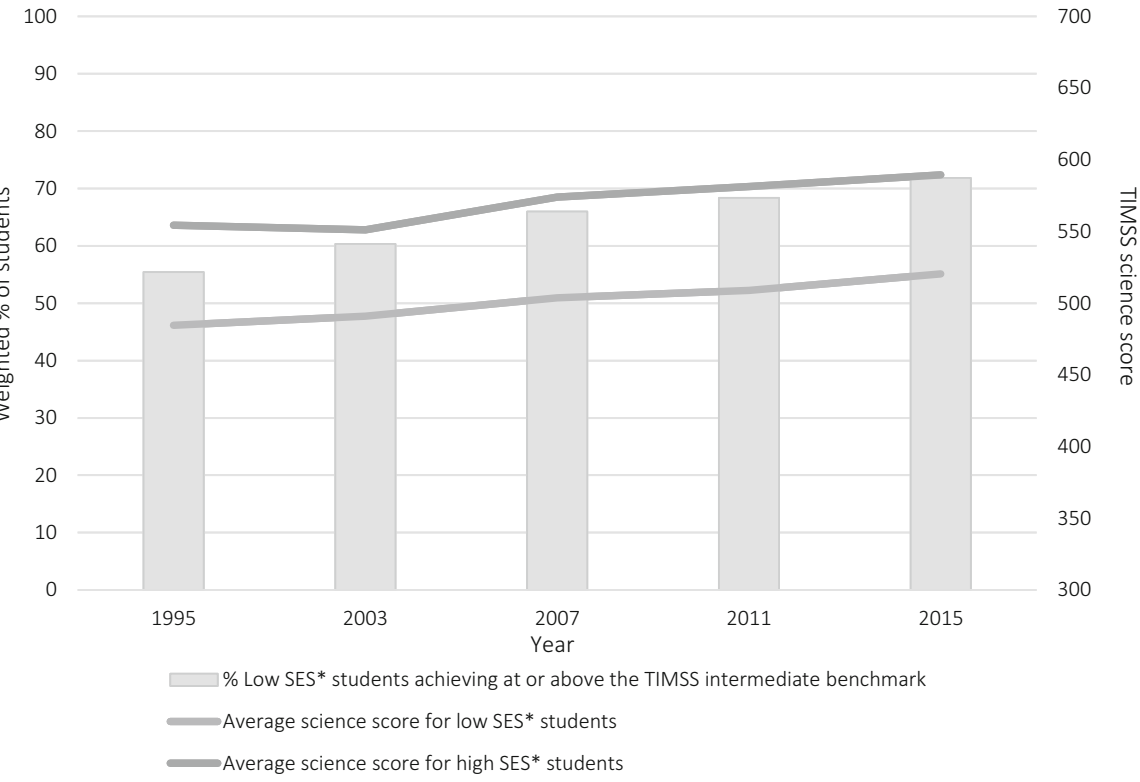

Fig. 4.26 Percentage of low-SES* students achieving at or above the TIMSS intermediate benchmark and the average science score for low- and high-SES* groups for Slovenia (1995-2015) 
about $14 \%$ in 2001 to $10 \%$ in 2013 . Government expenditure on education as a percentage of GDP remained at more or less the same level $(5 \%$ in $1995 ; 6 \%$ in 2012). The Gini index for Slovenia also remained stable over time (25 in 2004; 26 in 2014). Although there was no change in income inequality and little overall change in performance between 1995 and 2015, educational inequality decreased, as evidenced by the significant decline in SES* achievement gaps for mathematics over the 20 years of TIMSS. This might be related to Slovenia's proactive efforts in addressing achievement gaps between specific subgroups, as mentioned in OECD's education policy outlook for Slovenia (OECD 2016).

\subsubsection{Sweden}

Sweden has a highly decentralized education system and provides nine years of compulsory education for all children. The Swedish school system is structured around grades; grade one is the first year of compulsory schooling, while grade 12 is the last year of secondary education. Most of the school budgets in Sweden are funded by municipalities. The various Swedish institutions, municipalities, and central authorities implement educational policies that are in line with the governmental framework, while the Swedish government and parliament decide the outline of the national curriculum (Axelsson 2016).

Sweden has participated in most cycles of TIMSS since 1995, with the exception of the 1999 cycle. There were minor reductions in the achievement gap between high- and low-SES* students in both mathematics and science during the first 10 years of TIMSS, and increases in the achievement gap over the second decade of TIMSS (Figs. 4.27 and 4.28). As an example, the science achievement gap between high- and low-SES* students decreased from 85 points in 1995 to 69 points in 2003; this, however, was not statistically significant. The science achievement gap subsequently increased to 73 points in 2007, 86 points in 2011, and 94 points in 2015. This 24-point increase between 2003 and 2015 represents a significantly widening SES* achievement gap.

While the gap was closing (between 1995 and 2003), fewer low-SES* students were achieving at or above the TIMSS intermediate benchmark. For example, for science, $67 \%$ of low-SES* students achieved at or above that benchmark in 1995, and this figure declined to $59 \%$ in 2003 . Therefore, the decreasing achievement gap from 1995 to 2003 was a result of a sharp decline in both high- and low-SES* students' performance, with the low-SES* group declining less severely than the high-SES* group. Furthermore, the percentage of low-SES* students achieving at or above the TIMSS intermediate benchmark increased from $49 \%$ in 2007 and $46 \%$ in 2011, to 52\% in 2015. However, the increase in low-SES* students' performance was not as steep as it was for high-SES* students. Therefore, although more low-SES* students achieved at or above the intermediate benchmark, the achievement gap after 2007 has still been increasing. 
90

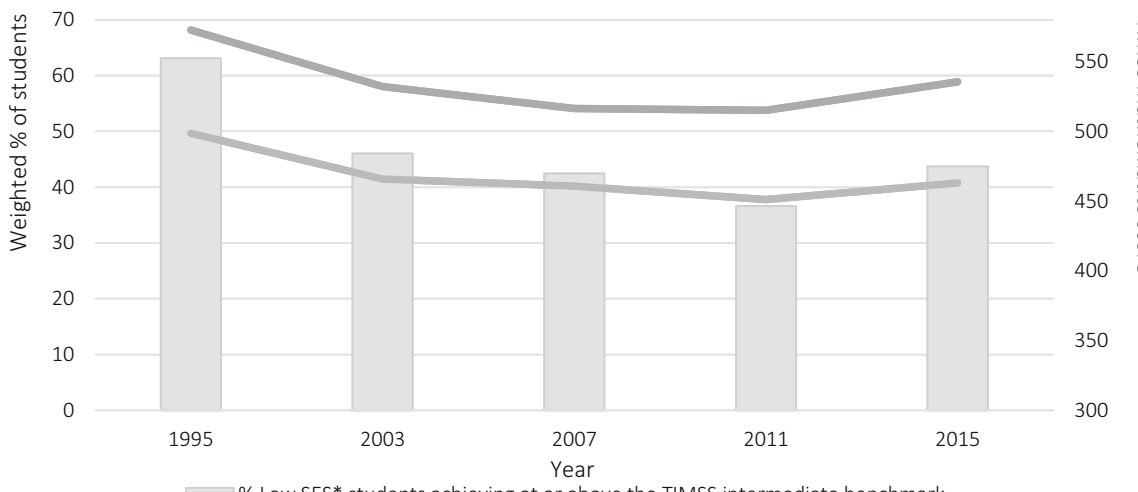

$\square$ \% Low SES* students achieving at or above the TIMSS intermediate benchmark

Average mathematics score for low SES* students

Average mathematics score for high SES* students

Fig. 4.27 Percentage of low-SES* students achieving at or above the TIMSS intermediate benchmark and the average mathematics score for low- and high-SES* groups for Sweden (1995-2015)



Fig. 4.28 Percentage of low-SES* students achieving at or above the TIMSS intermediate benchmark and the average science score for low- and high-SES* groups for Sweden (1995-2015) 
GDP per person in Sweden has been progressively increasing over the 20-year study period from US\$29,914 in 1995 to US\$ 50,812 in 2015. Meanwhile, more public expenditure has been focused on education. The percentage of total government expenditure allocated to education has been continuously growing, from $10 \%$ in 1995 to almost $15 \%$ in 2014. Likewise, the percentage of GDP spent on education has increased from $6 \%$ in 1995 to almost $8 \%$ in 2013. The trend in the Gini index for Sweden (26 in 2004; 27 in 2014) suggests there were no major changes in income inequality over that time period. However, we observed a statistically significant increase in the SES* achievement gap for science in the second decade of TIMSS, which was unexpected given Sweden's increased investment in education. Analyzing and understanding this discrepancy seems an important topic for future research efforts.

\subsubsection{United States}

The United States provides compulsory education for all children, varying by state, from between five years old to as high as 18 years old. In the United States, there is no nationwide education curriculum. Local school districts and state education agencies are responsible for subject area curriculum frameworks (US Department of Education 2008). Typically, kindergarten or grade one is the first year of compulsory schooling while grade 12 is the last year of secondary education. Funding for public education in the United States is provided by federal, state, and local governments, and public schools are free for all children from kindergarten through grade 12 .

The United States has participated in every cycle of the TIMSS assessment since 1995. The United States was the only country that experienced an overall significant decrease in the SES* achievement gap for science between high- and low-SES* students over the 20-year period studied (Fig. 4.29). While there was no statistical difference in the achievement gap between high- and low-SES* students in science between 1995 (105 points) and 2003 (93 points) and the decrease of 11 points in the SES* achievement gap between 2003 and 2015 was also not statistically significant, the overall decrease of 22 points from 1995 to 2015 (82 points) was significant. SES* achievement gaps for mathematics displayed similar patterns, although the difference was not significant (Fig. 4.30).

Around $45 \%$ of low-SES* students achieved at or above the TIMSS intermediate benchmark in the United States for science in both 1995 and 1999. This increased to more than 50\% in 2003, 2007, and 2011. By 2015, almost 60\% of low-SES* students were achieving at or above the TIMSS intermediate benchmark, suggesting a continuing improvement in low-SES* students' performance in the United States, and providing an explanation for the decrease in the SES* achievement gap. To conclude, the United States is an example of a country that has seen an improvement in the science performance of its most disadvantaged students during the 20 years of TIMSS, as well as a slowly decreasing SES* achievement gap. Results for mathematics were similar. 
90

70
60
50
40
30



40

30

20

10

0

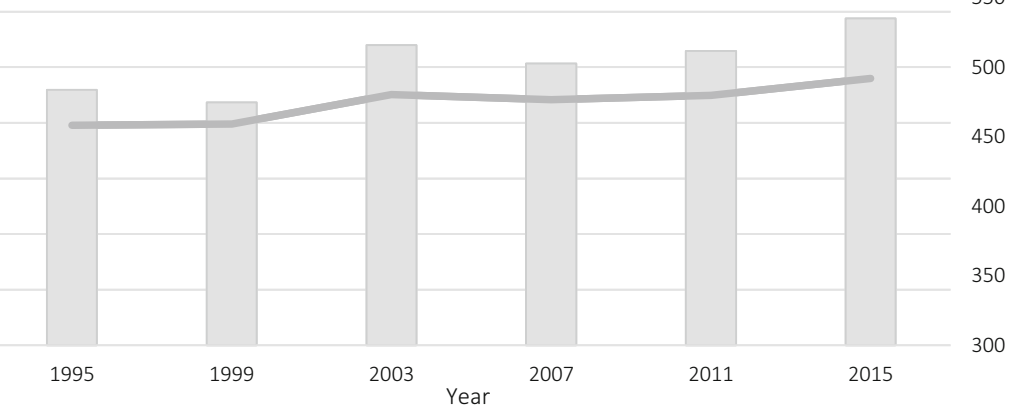

$\square$ \% Low SES* students achieving at or above the TIMSS intermediate benchmark

Average science score for low SES* students

Average science score for high SES* students

Fig. 4.29 Percentage of low-SES* students achieving at or above the TIMSS intermediate benchmark and the average science score for low- and high-SES* groups for the United States (1995-2015)

100

90

80

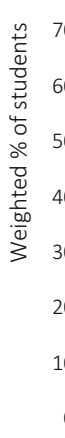

60

50

20

10

0

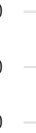

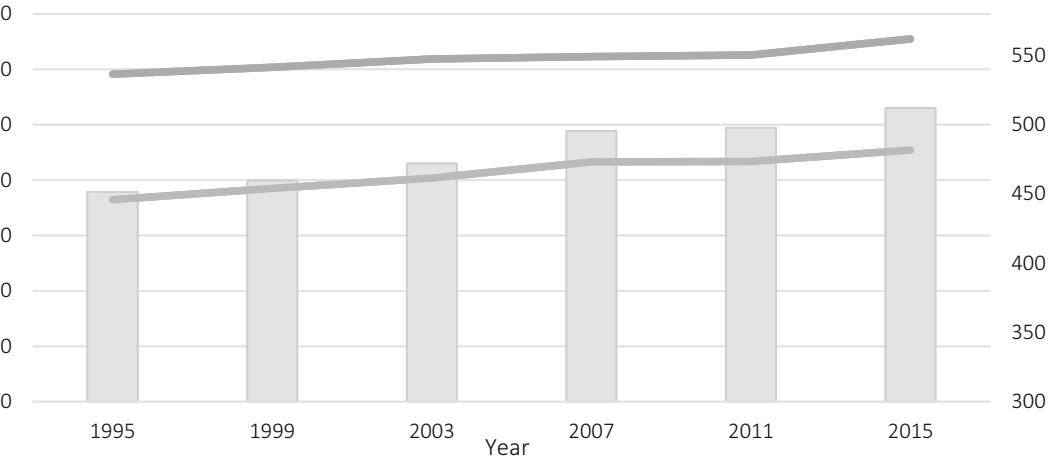

$\square$ \% Low SES* students achieving at or above the TIMSS intermediate benchmark

Average mathematics score for low SES* students

Average mathematics score for high SES* students

Fig. 4.30 Percentage of low-SES* students achieving at or above the TIMSS intermediate benchmark and the average mathematics score for low- and high-SES* groups for the United States (1995-2015) 
In the United States, GDP per person has been steadily increasing, from US\$ 28,782 in 1995 to US\$ 56,469 in 2015. The percentage of GDP spent on education has remained around $5 \%$ over that period. However, the percentage of total government expenditure allocated to education continuously decreased, from about $17 \%$ in 2002 to $13 \%$ in 2013. The United States' Gini index remained around 40 over the period 1995 to 2015 . In spite of a reduction in government spending on education, our findings suggest there was a significant reduction in the SES* achievement gap across the years for science, and for mathematics the there was also a decline, albeit one that was not significant over the 20 -year time period studied. Additional analyses are needed to further understand these contrasting results.

\section{References}

Australian Government. (2018). How are schools funded in Australia? Canberra: Department of Education and Training. Retrieved from https://www.education.gov.au/how-are-schoolsfunded-australia

Axelsson, M. (2016). Sweden. In I.V.S. Mullis, M.O. Martin, Goh, S., \& K. Cotter (Eds.) TIMSS 2015 encyclopedia: Education policy and curriculum in mathematics and science. Chestnut Hill: TIMSS \& PIRLS International Study Center, Boston College. Retrieved from http:// timssandpirls.bc.edu/timss2015/encyclopedia/countries/sweden/

Byun, S. Y., \& Kim, K. K. (2010). Educational inequality in South Korea: The widening socioeconomic gap in student achievement. In Globalization, changing demographics, and educational challenges in East Asia (pp. 155-182). Bingley: Emerald Group Publishing Limited.

Caygill, R., \& Flockton, J. (2016). New Zealand. In I.V.S. Mullis, M.O. Martin, Goh, S., \& K. Cotter (Eds.) TIMSS 2015 encyclopedia: Education policy and curriculum in mathematics and science. Chestnut Hill: TIMSS \& PIRLS International Study Center, Boston College. Retrieved from http://timssandpirls.bc.edu/timss2015/encyclopedia/countries/new-zealand/

Gini, C. (1921). Measurement of inequality of incomes. The Economic Journal, 31(121): 124-126. Retrieved from https://www.jstor.org/stable/pdf/2223319.pdf

Kovaleva, G., \& Krasnianskaia, K. (2008). Russian Federation. In I.V.S. Mullis, M.O. Martin, J.F. Olson, D.R. Berger, D. Milne, \& G.M. Stanco (Eds.), TIMSS 2007 encyclopedia. A guide to mathematics and science education around the world, Volume 2 (pp. 491-504). Chestnut Hill: TIMSS \& PIRLS International Study Center, Boston College. Retrieved from https:// timssandpirls.bc.edu/TIMSS2007/PDF/T07_Enc_V2.pdf

Lee, J. (2001). Education policy in the Republic of Korea: Building block or stumbling block? Washington, DC: World Bank Institute.

Ministry of Education, Science and Sport. (2015). The education system in the Republic Slovenia. Retrieved from http://203.gvs.arnes.si/BROSURA-vzgoja-in-izobrazevanje-v-RS-ENG/\#1

Ministry of Education, Singapore. (2016). Education system. Retrieved from https://www.moe.gov. sg/education/education-system

Mullis, I. V., Martin, M. O., \& Loveless, T. (2016). 20 Years of TIMSS: International trends in mathematics and science achievement, curriculum, and instruction. Chestnut Hill: TIMSS and PIRLS International Study Center, Boston College. Retrieved from http://timss2015.org/ timss2015/wp-content/uploads/2016/T15-20-years-of-TIMSS.pdf.

Norwegian Directorate for Education and Training. (2014). The education mirror 2014. Oslo: Author. 
Nuffic. (2015). Education system Iran described and compared with the Dutch system (2nd ed.). The Hague: Nuffic. The Dutch Organization for Internationalisation in Education.

OECD. (2011). Lessons from PISA for the United States, Strong performers and successful reformers in education. Paris: OECD Publishing. Retrieved from http://dx.doi.org/10.1787/ 9789264096660-en

OECD. (2016). Education policy outlook: Slovenia. Paris: OECD. Retrieved from http://www. oecd.org/education/Education-Policy-Outlook-Country-Profile-Slovenia.pdf

OECD. (2017). Education in Lithuania (Reviews of national policies for education). Paris: OECD Publishing. Retrieved from https://doi.org/10.1787/9789264281486-en

The Government of the Hong Kong Special Administration Region Education Bureau. (2018). Overview on secondary education. Retrieved from https://www.edb.gov.hk/en/edu-system/ primary-secondary/secondary/overview/index.html

US Department of Education. (2008). Organization of US education. State role I-Primary and secondary education. Washington, DC: US Network for Education Information, US Department of Education. Retrieved from http://www2.ed.gov/about/offices/list/ous/ international/usnei/us/edlite-org-us.html

Open Access This chapter is licensed under the terms of the Creative Commons AttributionNonCommercial 4.0 International License (http://creativecommons.org/licenses/by-nc/4.0/), which permits any noncommercial use, sharing, adaptation, distribution and reproduction in any medium or format, as long as you give appropriate credit to the original author(s) and the source, provide a link to the Creative Commons license and indicate if changes were made.

The images or other third party material in this chapter are included in the chapter's Creative Commons license, unless indicated otherwise in a credit line to the material. If material is not included in the chapter's Creative Commons license and your intended use is not permitted by statutory regulation or exceeds the permitted use, you will need to obtain permission directly from the copyright holder.



